\title{
An efficient bio-inspired catalytic tool for hydrogen release at room temperature from a stable borohydride solution
}

Laura Birba, ${ }^{\text {a,b }}$ Vincent Ritleng, ${ }^{\mathrm{c}, \mathrm{d}}$ Loïc Jierry, ${ }^{\mathrm{e}}$ Géraldine Agusti, ${ }^{\mathrm{a}}$ Pascal Fongarland, ${ }^{\mathrm{b}}$ David Edouard $^{\mathrm{a}, \mathrm{b} *}$

a. Laboratoire d'Automatique, de Génie des Procédés et Génie Pharmaceutique, LAGEPP, Université Claude Bernard Lyon 1, CNRS, 43 boulevard du 11 novembre 1918, F-69100, VILLEURBANNE, France

b. Laboratoire de Génie des Procédés Catalytiques, LGPC, CNRS, CPE-Lyon, Université Claude-Bernard Lyon 1, 43 boulevard du 11 Novembre 1918, F-69100, VILLEURBANNE, France

c. Université de Strasbourg, Ecole européenne de Chimie, Polymères et Matériaux, CNRS, LIMA, UMR 7042, 25 rue Becquerel, 67087 Strasbourg, France.

d. Institut Universitaire de France, 1 rue Descartes, 75231 Paris, France.

e. Université de Strasbourg, CNRS, Institut Charles Sadron, UPR 022, 23 rue du Loess, 67034 Strasbourg, France.

* To whom all correspondence should be addressed: E-mail: david.edouard@univ-lyon1.fr

\begin{abstract}
Commercially available open cell polyurethane foams (OCPUF) have been successively functionalized with bio-inspired polydopamine coating (OCPUF@PDA), and activated with cobalt nanoparticles (OCPUF@PDA@Co). The resulting Soft Structured Catalytic Support $\left(\mathrm{S}_{2} \mathrm{CS}\right)$ has been used as a highly efficient tool for the release of dihydrogen from a commercially available alkaline sodium borohydride solution at room temperature. With a diluted solution containing $0.4 \mathrm{wt} . \% \mathrm{NaBH}_{4}$ and 0.4 wt. $\% \mathrm{NaOH}$, the hydrogen generation rate was of $76.4 \pm 3.18 \mathrm{~L} \cdot \mathrm{h}^{-1} \cdot \mathrm{g}_{\mathrm{cat}}{ }^{-1}$ after stabilisation of the catalytic activity. The catalytic tool could be used for 10 runs.
\end{abstract}




\section{KEYWORDS}

Bio-inspired Soft Structured Catalytic Support; Polyurethane Open Cell Foam; Polydopamine; $\mathrm{H}_{2}$ storage; $\mathrm{NaBH}_{4}$ stable solution; Hydrogen production.

\section{INTRODUCTION}

In the current context of global warming, industries and transportations are required to less depend on fossil fuel energy and to reduce their carbon footprint. Hydrogen, as a carbon-free energetic vector, is a promising source of energy. ${ }^{1}$ Indeed, the energy density of hydrogen is around three times higher than that of gasoline. ${ }^{2}$ Besides, hydrogen is used as a reagent in the chemical industry, notably for the production of ammonia or urea. It is also widely used in the crude oil refining, the Fischer-Tropsch reaction, and in the transport and metallurgy fields. However, hydrogen is scarce in its elemental form as it is not a major air component; consequently, many processes have been developed for its production and storage. Around $96 \%$ of hydrogen is sourced from fossil fuels (i.e. natural gas, liquid hydrocarbons and coal). ${ }^{2,3}$ Steam reforming and gasification are the main industrial processes for the syngas (mixture of $\mathrm{H}_{2}$ and $\mathrm{CO}$ ) production, ${ }^{4}$. Despite steam reforming is largely employed as an economical pathway for $\mathrm{H}_{2}$ production, it requires to be coupled to gas separation and $\mathrm{CO}_{2}$ conversion units in order to limit the release of greenhouse effect gas. In this context, carbonfree processes such as photochemical cells, water splitting or photo-biological processes are promising technologies for the production of $\mathrm{H}_{2}$. In particular, water electrolysis is a wellestablished technology that provides around $4 \%$ of the overall production of $\mathrm{H}_{2}$, and leads to ultra-pure $\mathrm{H}_{2}$ production. ${ }^{3}$ However, these pathways require a high electric or thermic energy input to be achieved, ${ }^{3,5}$ and would require the use of renewable sources of energy (solar or wind) to be really carbon free. ${ }^{6}$

In addition to the carbon-free and eco-efficient production of $\mathrm{H}_{2}$, another challenge is the storage of $\mathrm{H}_{2}$ since it has a very low volumetric energy density (i.e.: around $0.0823 \mathrm{~kg} / \mathrm{m}^{3}$ at ambient temperature). ${ }^{7}$ Gas compression, which is actually the main storage technique, allows to reach a volumetric energy density of $39.22 \mathrm{~kg} / \mathrm{m}^{3}$ at 700 bar and $25^{\circ} \mathrm{C}$. ${ }^{8,9}$ However, such a process involves high pressures and/or cryogenic temperatures (cryo-compression, liquefaction) and is thus highly energy demanding. ${ }^{10}$ In addition, such conditions are not adequate for a safe and economic transportation of the gas. 
In this context, chemical hydrides have been widely accepted as promising storage materials for delivering $\mathrm{H}_{2}$ gas to fuel cells. Pure hydrogen is recoverable by simple hydrolysis of the hydride at room temperature and atmospheric pressure (Equation (1)). ${ }^{11}$ Sodium borohydride $\left(\mathrm{NaBH}_{4}\right)$ stands out due to: (a) its high hydrogen storage capacity $(10.6 \mathrm{wt} \%)$, (b) the possible fine control of the $\mathrm{H}_{2}$ production in alkaline solutions, ${ }^{11}$ and (c) the fact that the by-product of the hydrolysis reaction, $\mathrm{NaBO}_{2}$, is environmentally safe and can be readily recycled to $\mathrm{NaBH}_{4}{ }^{12,13}$ Moreover, $\mathrm{NaBH}_{4}$ solutions are easily commercially available at medium cost. Nevertheless, in the case where a stable alkaline solution of $\mathrm{NaBH}_{4}$ is used for hydrogen storage, a suitable catalyst for $\mathrm{H}_{2}$ release is necessary.

$$
\mathrm{NaBH}_{4}+2 \mathrm{H}_{2} \mathrm{O} \rightarrow \mathrm{NaBO}_{2}+4 \mathrm{H}_{2}
$$

In the open literature, many studies propose interesting highly efficient catalysts. ${ }^{14-16}$ However, generally these catalysts are under powder form and are not compatible with process intensification (e.g. continuous process). The main drawbacks with catalytic powders include high pressure drop, low catalyst recyclability and process engineering. ${ }^{17}$ In this context, catalysts supported on a structured support have already proven their superiority in terms of process engineering and catalyst recyclability. ${ }^{18,19}$ Among these supports, open cell foams are exciting tools since they allow an important surface over volume ratio, a small pressure loss even at high flow, ${ }^{20,21}$ efficient mass transfers, an intimate mixing of the reagents, ${ }^{22,23}$ and an easy separation from the solution (e.g. stock, load or recyclability operations); in other words, no filtration step is required in contrast to catalyst powder. Nickel based open cell foams have already proven their potential as structured catalytic supports for on-board hydrogen generation from $\mathrm{NaBH}_{4}$ hydrolysis. ${ }^{24,25}$ However, the main limits of such catalytic foams are their energy consuming and non-eco-friendly preparation method and their poor mechanical resistance due to their rigid struts. ${ }^{26}$

Consequently, our challenge was to design an eco-friendly supported catalytic tool in order to efficiently release $\mathrm{H}_{2}$ from a stable commercially available alkaline sodium borohydride solution at room temperature. Regarding the supported catalytic tool, the choice of the support (cost, easy preparation, mechanical properties ...) is crucial to the design of process. Thus, the challenge consisted in developing an efficient, cheap, stable and eco-friendly tool $\left(\mathrm{S}_{2} \mathrm{CS}\right)$. To achieve this purpose, we have used Open Cell Polyurethane Foams (OCPUF) (Figure 1) as structured supports. OCPUF are lightweight structures that are 
commercially available at low cost due to the large variety of applications involving their physical and mechanical properties. ${ }^{27}$ However, using OCPUF as catalytic support precludes heat treatments (calcination, reduction step ...) as polyurethanes have typically a fusion temperature below or around $100{ }^{\circ} \mathrm{C}$.

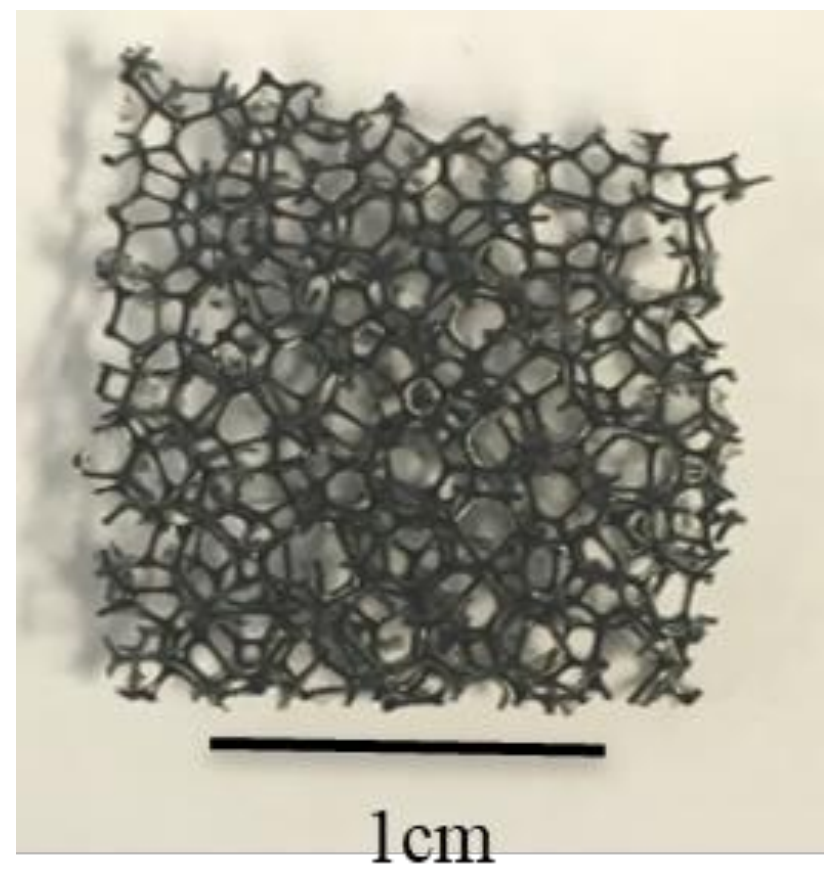

Figure 1. Commercially available polyurethane open cell foam used in this work

Inspired both by the adhesive and reducing properties of polydopamine (PDA) and our previous works, ${ }^{28-30}$ the polyurethane open cell foams were pre-functionalized with a polydopamine layer (OCPUF@PDA) to offer sufficient stability to a cobalt active phase. The choice of cobalt as the active phase was driven by the necessity to keep the costs as low as possible and to use earth-abundant metals. In addition, Co particles have been often reported to behave as a highly efficient catalyst for $\mathrm{H}_{2}$ generation from $\mathrm{NaBH}_{4} \cdot{ }^{31-35}$

The metal-binding and redox abilities of the polydopamine layer served both to immobilize the cobalt active particles on the surface of open cell foams and to protect these particles from possible oxidation. ${ }^{36-37}$ The generated Soft Structured Catalytic Support was then used for $\mathrm{H}_{2}$ generation from a commercially available stable alkaline solution of sodium tetrahydridoborate, and we report here that the OCPUF@PDA-supported cobalt catalyst exhibited remarkable activity, stability and reusability. 


\section{EXPERIMENTAL SECTION}

\subsection{Materials}

Commercial compounds were used as received. Dopamine hydrochloride, tris(hydroxymethyl)aminomethane buffer (TRIS), sodium acetate and Co nitrate were purchased from Alfa Aesar. Sodium borohydride powder ( $>98 \%$ purity) was purchased from Acros Organics. Sodium periodate was purchased from Sigma Aldrich. Polyurethane open cell foams (Fig. 1) were purchased from FoamPartner. Their characteristics are as follows: mean strut size: $220 \mu \mathrm{m}$; mean window size: $779 \mu \mathrm{m}$; mean cell size: $2500 \mu \mathrm{m}$; density: 0.027-0.033, porosity: 0.94-0.97. Cubic samples of $7 \mathrm{~cm}^{3}$ (194 $\mathrm{mg} \pm 21 \mathrm{mg}$ ) were used without prior treatment. Aqueous solutions were prepared with water purified by Synergy ${ }^{\circledR}$ Water Purification System (Millipore). Alkaline $\mathrm{NaBH}_{4}$ stabilized solution, namely "Redubore 2020", was purchased from H\&V Chemicals. The commercially available solution contains $20 \mathrm{wt} \% \mathrm{NaBH}_{4}$ in $20 \mathrm{wt} \% \mathrm{NaOH}$.

\subsection{Characterisation techniques}

Scanning electron microscopy was performed with a Hitachi S800 FEG microscope at the "Centre Technologique des Microstructures" (CT $\mu)$ at the University of Lyon. Samples of OCPUF,OCPUF@PDA or OCPUF@PDA@Co were deposited on a flat steel holder and coated under vacuum by cathodic sputtering with platinum. The samples were observed by SEM under an accelerating voltage of $15 \mathrm{kV}$. Elemental analyses were performed with an EDS-SDD detector (SAMx) with an active area of $30 \mathrm{~mm}^{2}$. ICP-AES measurements were performed by the Plateforme Analytique of the Institut Pluridisciplinaire Hubert Curien (UMR CNRS 7178), Strasbourg, France. X-ray photoelectron (XPS) spectra were acquired on a Thermo Fischer VGMultilabESCA3000 under ultra-high vacuum; the baseline was subtracted from the spectra, the calibration was performed by adventitious carbon at $284.8 \mathrm{eV}$ and data were analysed by CASAXPS version 2.3 .15 software.

\subsection{Preparation of OCPUF@PDA and of OCPUF@PDA/Fe foams}

OCPUF@PDA foams were prepared by immersion of samples of OCPUF $\left(7 \mathrm{~cm}^{3}\right)$ in an aqueous buffered solution of dopamine $(2 \mathrm{mg} / \mathrm{mL})$ at room temperature with magnetic 
stirring for $24 \mathrm{~h}$. Then the samples are dried at $70{ }^{\circ} \mathrm{C}$ and washed 5 times with water. Two methods of PDA deposition on polyurethane support were compared. The first one consisted in immersing the OCPUF sample in a TRIS- $\mathrm{HCl}$ buffered solution $(10 \mathrm{mM}, \mathrm{pH} 8.5)$ containing dopamine. ${ }^{37}$ The second one consisted in using sodium periodate $\left(\mathrm{NaIO}_{4}, 20 \mathrm{mM}\right)$ as a chemical oxidant in a sodium acetate buffered solution $(50 \mathrm{mM}, \mathrm{pH} 5)$ containing dopamine. ${ }^{38}$

As the resulting OCPUF@PDA(TRIS) and OCPUF@PDA(NaIO 4 ) foams are intended to be used as structured catalytic support for the hydrolysis of $\mathrm{NaBH}_{4}$ from a stable alkaline solution ( $\mathrm{pH}$ 12-14), the chemical stability of the PDA coating must be ensured under these very basic conditions. To enhance the stability of a PDA film under harsh alkaline conditions, Kim and co-workers reported a simple method that consisted in treating the PDA coated solid with a $\mathrm{FeCl}_{3}$ solution. ${ }^{39}$ This procedure leads to $\mathrm{Fe}(+\mathrm{III})$ complexation by the PDA catechol groups, and prevents PDA leaching at elevated pH. As a consequence, OCPUF@PDA foams were dipped in an $\mathrm{EtOH}$ solution containing $\mathrm{FeCl}_{3}(10 \mathrm{mM})$ at room temperature for $1 \mathrm{~h}$ and dried under vacuum before cobalt particles deposition. The thus prepared samples are noted OCPUF@PDA(TRIS)/Fe and OCPUF@PDA(NaIO $\left.\mathrm{N}_{4}\right) / \mathrm{Fe}$, respectively. The resulting samples were characterised by SEM and EDX analysis.

\subsection{Preparation of $\mathrm{PDA}\left(\mathrm{NaIO}_{4}\right) / \mathrm{Fe}$ powder}

A PDA powder was prepared by adding dopamine $(2 \mathrm{mg} / \mathrm{mL})$ to a buffered solution of sodium acetate $(50 \mathrm{mM}, \mathrm{pH} 5)$ containing $\mathrm{NaIO}_{4}(20 \mathrm{mM})$. The solution was stirred for $24 \mathrm{~h}$ at $200 \mathrm{rpm}$ at room temperature. The resulting particles were collected by centrifugation (10 min, $7000 \mathrm{rpm}$ ), washed three times with $\mathrm{H}_{2} \mathrm{O} / \mathrm{EtOH}$ (1:1), and one time with EtOH. After characterization by SEM, the $\mathrm{PDA}\left(\mathrm{NaIO}_{4}\right)$ particles were dipped in a $\mathrm{FeCl}_{3}$ solution $(10 \mathrm{mM}$, in $\mathrm{EtOH}$ ) during $1 \mathrm{~h}$ at room temperature under magnetic stirring and collected by centrifugation. The particles were then dried at $70{ }^{\circ} \mathrm{C}$ under atmospheric pressure. The resulting $\mathrm{PDA}\left(\mathrm{NaIO}_{4}\right) / \mathrm{Fe}$ particles were finally hand-milled and sieved at $40 \mu \mathrm{m}$.

\subsection{Cobalt active particles deposited on OCPUF@PDA/Fe}

An OCPUF@PDA(TRIS)/Fe or OCPUF@PDA(NaIO 4$) / F e$ sample $\left(7 \mathrm{~cm}^{3}\right)$ was immersed in an aqueous $\mathrm{Co}\left(\mathrm{NO}_{3}\right)_{2}$ solution $(1.02 \mathrm{~g}, 70 \mathrm{mM}, 50 \mathrm{~mL})$, and an aqueous solution of $\mathrm{NaBH}_{4}$ $(1.9 \mathrm{~g}, 2 \mathrm{M}, 25 \mathrm{~mL}$ ) was added dropwise at a rate of 2 to $3 \mathrm{~mL} / \mathrm{min}$ with constant stirring 
while the temperature was kept between 1 and $5{ }^{\circ} \mathrm{C}$. The sample was kept in the solution under stirring for $2 \mathrm{~h}$, pulled out of the solution, dried at $70{ }^{\circ} \mathrm{C}$ for $4 \mathrm{~h}$ under vacuum, and washed with distilled water. The resulting OCPUF@PDA( $\left(\mathrm{NaIO}_{4}\right) / \mathrm{Fe} @ \mathrm{Co}$ and OCPUF@PDA(TRIS)/Fe@Co materials were characterized by SEM, SEM-EDX, ICP-AES and XPS.

\subsection{General procedure and apparatus for $\mathrm{H}_{2}$ production}

In a typical experiment, a sample $\left(7 \mathrm{~cm}^{3}\right)$ of OCPUF, OCPUF@PDA/Fe or OCPUF@PDA/Fe@Co was immersed in 150 mL of an aqueous solution of $\mathrm{NaBH}_{4}(0.1$ M) or of a Redubore 2020 solution of $\mathrm{NaBH}_{4}$ diluted to $0.1 \mathrm{M}$, and maintained at $20{ }^{\circ} \mathrm{C}$ by a temperature-regulated bath. The reaction flask was hermetically connected to a $100 \mathrm{~mL}$ graduated burette to quantify the $\mathrm{H}_{2}$ gas produced by volumetric measurement. ${ }^{40,41}$ The timer was launched as soon as the reaction flask was connected. The experimental set up is presented in Figure 2.

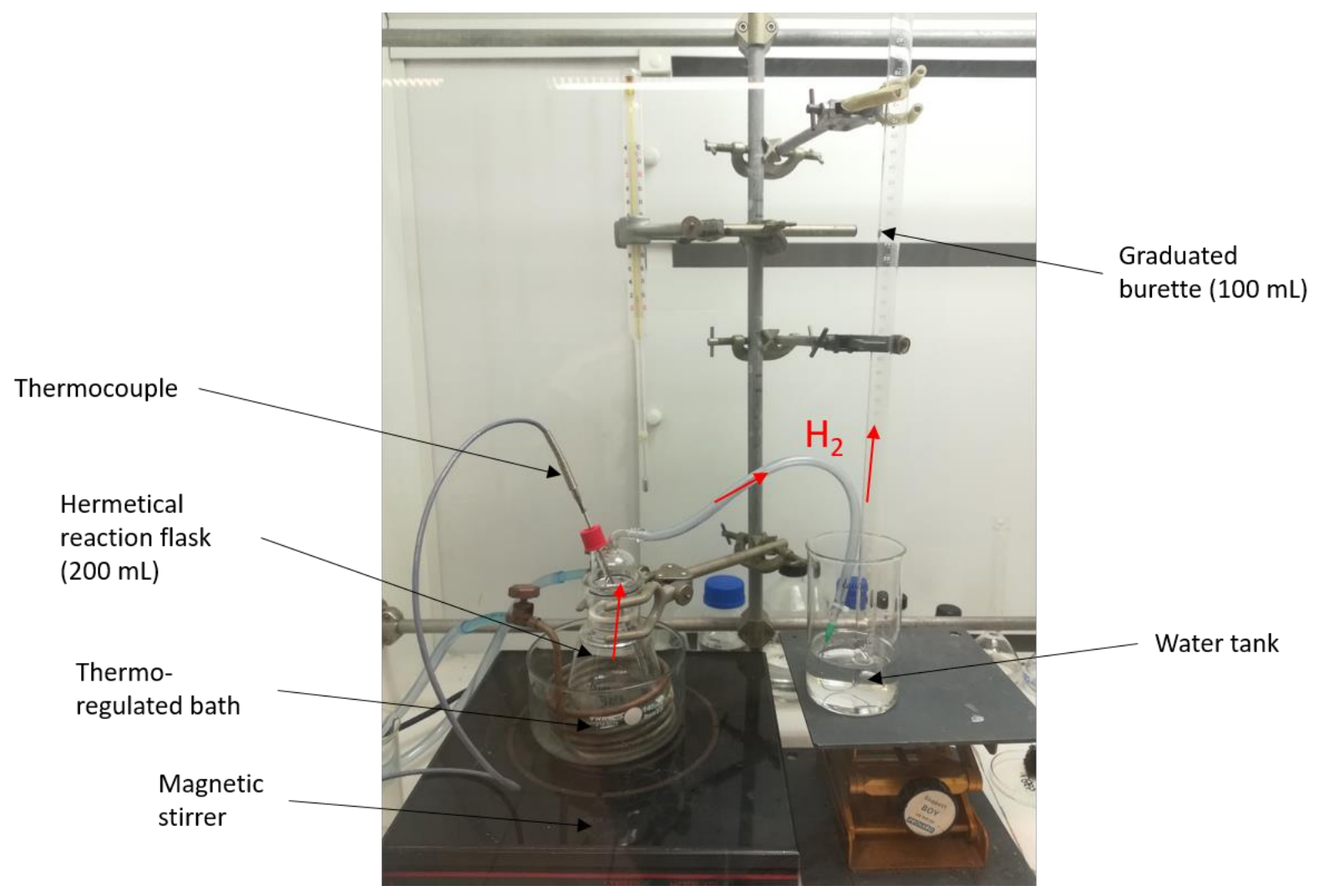

Figure 2. Experimental set up for the production of $\mathrm{H}_{2}$ by catalytic hydrolysis of $\mathrm{NaBH}_{4}$ 


\section{RESULTS AND DISCUSSION}

\subsection{Synthesis and characterization of the $\mathrm{PDA}\left(\mathrm{NaIO}_{4}\right) / \mathrm{Fe}$ powder, and of the OCPUF@PDA/Fe and OCPUF@PDA/Fe@Co foams}

OCPUF@PDA(TRIS) and OCPUF@PDA(NaIO 4$)$ were prepared by immersion of a piece of OCPUF in an aqueous buffered solution of dopamine at room temperature. In the presence of an oxidant, dissolved $\mathrm{O}_{2}$ or $\mathrm{NaIO}_{4}$, dopamine self-polymerises into PDA on the foam's surface. ${ }^{37,38}$ As mentioned in the experimental section, iron doping with $\mathrm{FeCl}_{3}$ was performed in order to increase the chemical stability of the PDA film under harsh alkaline medium. ${ }^{39}$ As expected, ${ }^{42}$ the PDA content on OCPUF was higher when $\mathrm{NaIO}_{4}$ (10 to 16 wt.\%) was used than when $\mathrm{O}_{2}$ (3 to 5 wt.\%) was used. Low magnification scanning electron microscopy (SEM) images of OCPUF@PDA/Fe revealed a rough coating of PDA on the whole surface of the polyurethane foam independently of the nature of the used oxidant (Figure 3B,C). However higher magnification images revealed textural differences of the PDA film with much thicker and larger plates in the case of OCPUF@PDA(NaIO 4$)($ Figure 3E) compared to OCPUF@PDA(TRIS) (Figure 3F). The EDX spectra of OCPUF@PDA(NaIO 4 or TRIS)/Fe confirmed the presence of iron on the foam's surface (Figure 3G).
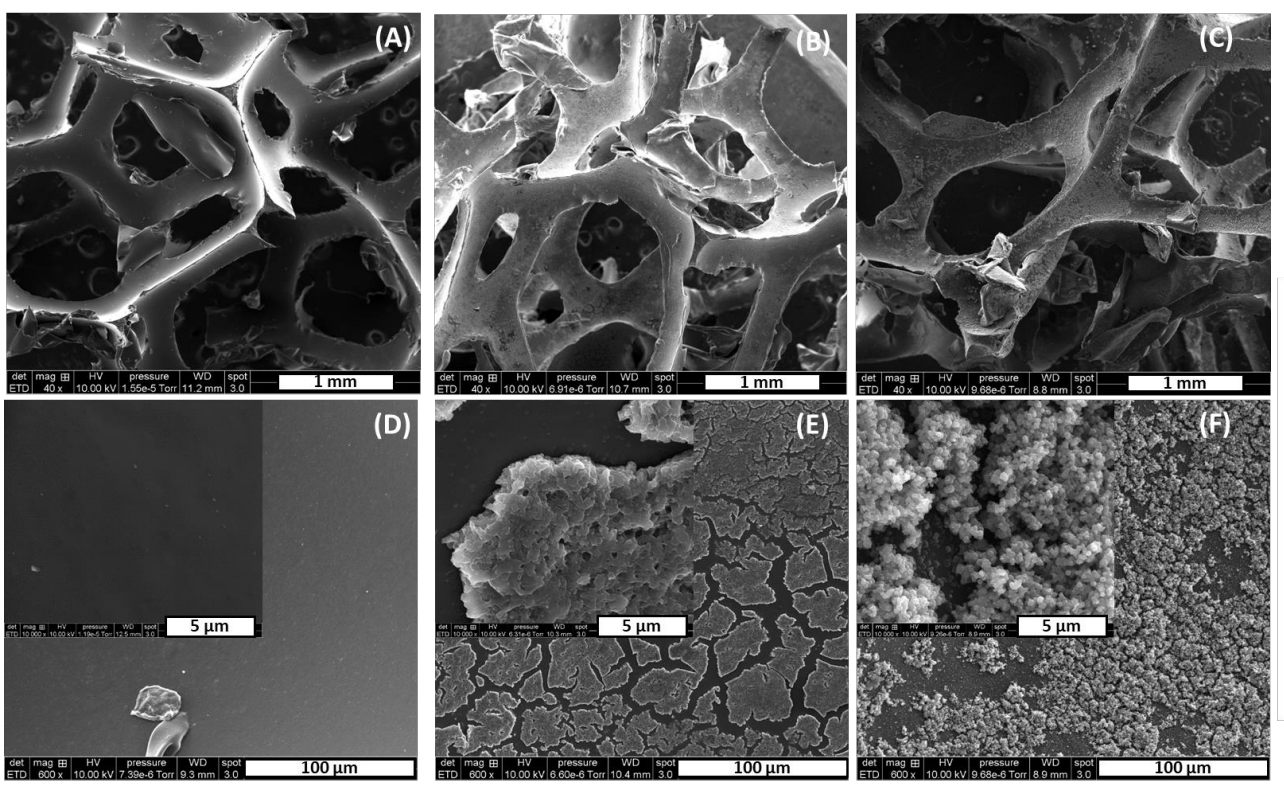

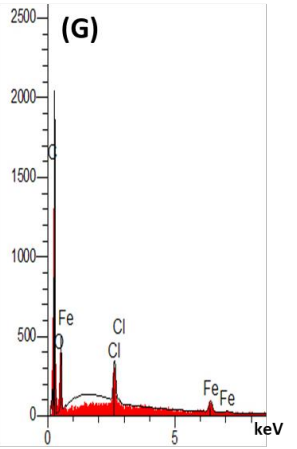

Figure 3. Low and high magnification SEM pictures of (A,D) OCPUF, $(B, E)$ OCPUF@PDA(NaIO 4$) / \mathrm{Fe}$ and (C,F) OCPUF@PDA(TRIS)/Fe. (G) EDX spectrum of OCPUF@PDA(TRIS)/Fe. 
To benchmark the hydrolysis activity of OCPUF-supported PDA with "free" PDA (powder), PDA $\left(\mathrm{NaIO}_{4}\right) / \mathrm{Fe}$ powder was also prepared. The preparation of PDA particles in the presence of $\mathrm{NaIO}_{4}$ as oxidant was chosen in order to reach the maximum mass of PDA powder. The obtained PDA particles have the appearance of a black powder, as shown in Figure 4A. PDA particles' agglomerates present a maximum size of $50 \mu \mathrm{m}$ whereas the smallest particles have a diameter below $1 \mu \mathrm{m}$ with random morphologies, as can be seen from the SEM images displayed in Figure 4B,C.
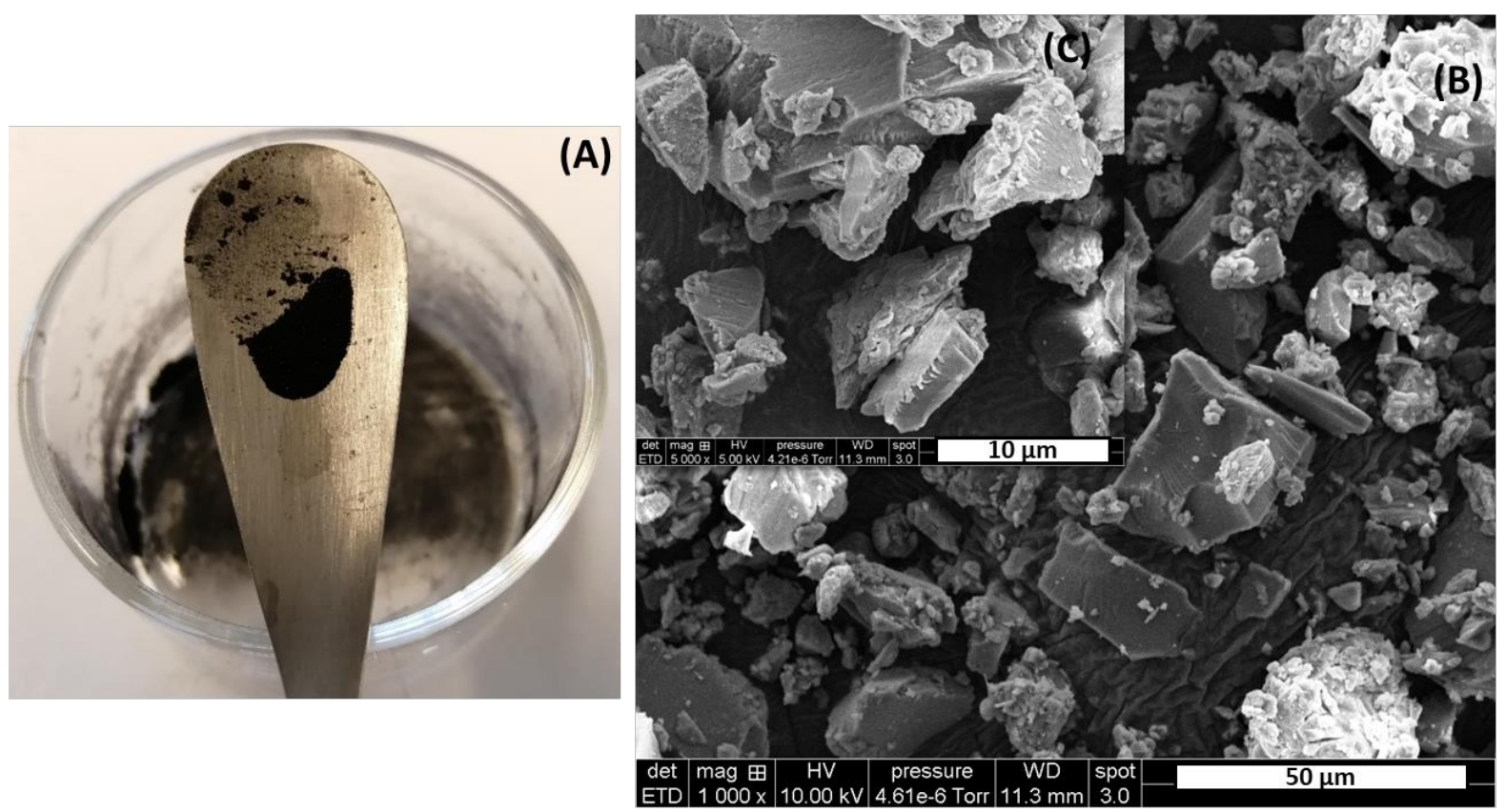

Figure 4. (A) Picture of a PDA(NaIO 4$)$ powder. (B) Low and (C) High magnification SEM pictures a $\mathrm{PDA}\left(\mathrm{NaIO}_{4}\right)$ powder.

OCPUF@PDA/Fe@Co foams were prepared by grafting cobalt particles on OCPUF@PDA(TRIS)/Fe or OCPUF@PDA(NaIO $\left.{ }_{4}\right) / \mathrm{Fe}$. According to the method published by Lefebvre et al., ${ }^{36}$ it is possible to use the redox properties of polydopamine-coated OCPUF in order to concomitantly synthesize and graft metal(0) nanoparticles on the foam surface (e.g. Ag NPs). In this work, we propose to improve the metal reduction by using a solution of $\mathrm{NaBH}_{4}$ as a reduction agent. ${ }^{42}$ The employed method took its inspiration from Delgado and collaborators' process that led to the synthesis of well dispersed, thin and highly active Co NPs on an anatase support. This process was carried out at room temperature in the presence 
of polyvinylpyrrolindole as a NPs size' stabiliser. ${ }^{43}$ In our case, a control of the process temperature between $1{ }^{\circ} \mathrm{C}$ and $5{ }^{\circ} \mathrm{C}$ was carried out to limit the particles size.

The resulting OCPUF@PDA(TRIS)/Fe@Co and OCPUF@PDA(NaIO 4$) / \mathrm{Fe} @ \mathrm{Co}$ materials were characterized by SEM micrographs combined to energy dispersive X-ray spectroscopy (EDX) (Figure 5). The EDX spectrum of OCPUF@PDA(TRIS)/Fe@Co confirmed the successful grafting of cobalt (Figure 5E). Low magnification SEM images of OCPUF@PDA(TRIS)/Fe@Co (Figure 5B) shows a relatively homogeneous deposition of cobalt particles on the PDA film. In contrast, more dispersed and much larger Co particles are observed in the case of OCPUF@PDA( $\left.\mathrm{NaIO}_{4}\right) / \mathrm{Fe} @ \mathrm{Co}$ (Figure 5A). Higher magnification pictures also reveal different types of cobalt deposition on the surface of the foam depending on the nature of the used oxidant, with aggregates of up to $30 \mu \mathrm{m}$ in the case of OCPUF@PDA $\left(\mathrm{NaIO}_{4}\right) / \mathrm{Fe} @ \mathrm{Co}$ (Figure 5C) and micrometric sponge-like aggregates in the case of OCPUF@PDA(TRIS)/Fe@Co (Figure 5D).
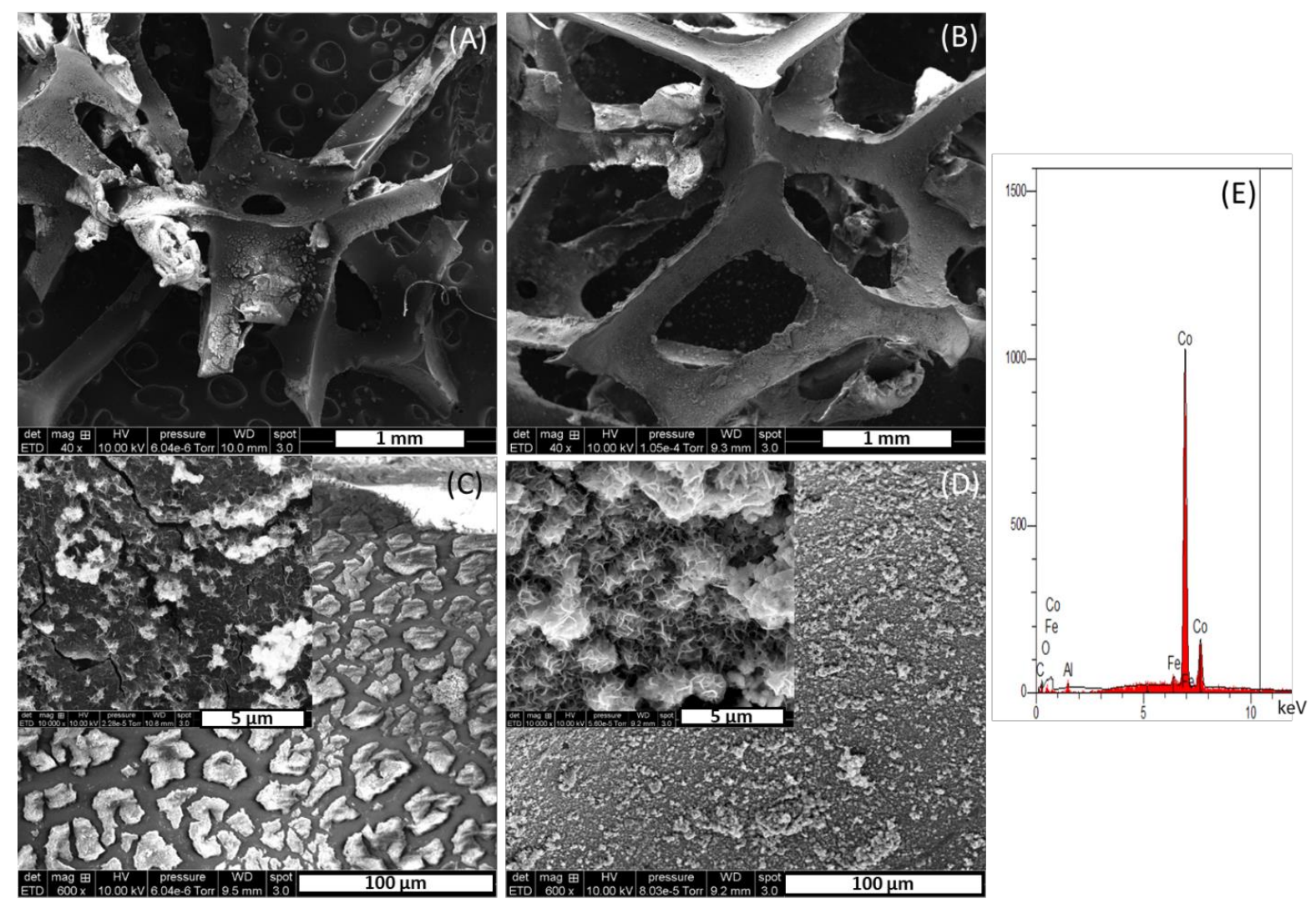

Figure 5. Low and high magnification SEM images of (A,C) OCPUF@PDA( $\left.\mathrm{NaIO}_{4}\right) / \mathrm{Fe} @ \mathrm{Co}$ and (B,D) OCPUF@PDA(TRIS)/Fe@Co. (E) EDX spectrum of OCPUF@PDA(TRIS)/Fe@Co. 
The masses of Co immobilized on OCPUF@PDA/Fe foams were estimated by simply weighing the foams before and after cobalt doping, as well as by ICP-AES measurements. The masses of cobalt measured by weighing are $5.8 \pm 1.0 \mathrm{mg}$ on OCPUF@PDA(TRIS)/Fe supports and between 1 to $30 \mathrm{mg}$ on OCPUF@PDA $\left(\mathrm{NaIO}_{4}\right) / \mathrm{Fe}$. In the latter case, the mass of cobalt varies a lot from one sample to another. We believe, this may be due to varying degrees of PDA(NaIO 4$)$ abrasion on OCPUF during the cobalt deposition step. The PDA coating is indeed thicker when $\mathrm{NaIO}_{4}$ is used as an oxidant (Figure 3E), and this is essentially due to an accumulation of PDA layers, which are less firmly bound to each other than the initial PDA layer on OCPUF foam.

Finally, X-ray Photoelectron Spectroscopy (XPS) analyses of OCPUF@PDA(TRIS), OCPUF@PDA(TRIS)/Fe and OCPUF@PDA(TRIS)/Fe@Co were performed. The XPS survey scans of OCPUF@PDA(TRIS) and OCPUF@PDA(TRIS)/Fe (Figures S1 and S2, ESI), respectively, show no and one $\mathrm{Fe} 2 \mathrm{p}$ peak near $714 \mathrm{eV}$, therefore confirming the successful complexation of Fe by the PDA layer on OCPUF@PDA(TRIS)/Fe, as published by Kim and co-workers. ${ }^{39}$ The XPS survey spectrum of OCPUF@PDA(TRIS)/Fe@Co (Figure S3, ESI) presents both Fe $2 p$ and Co $2 p$ peaks. The Fe $2 p$ peak is less intense than in OCPUF@PDA(TRIS)/Fe, perhaps due to some Fe leaching during the cobalt grafting process, and totally disappears after the catalytic tests (Figure S4, ESI), therefore confirming the leaching of the latter. We thus believe that Fe only plays a minor role in the hydrolysis process (if it does (vide infra)). In order to give information about the Co valence state to the reader, and thus about the nature of the probable active phase, the obtained Co $2 \mathrm{p}$ XPS spectra of OCPUF@PDA(TRIS)/Fe@Co before and after the catalytic runs are presented Figure 6. The Co $2 \mathrm{p}_{1 / 2}$ peak and its satellite are observed at 801 and $807 \mathrm{eV}$, respectively, and the Co $2 p_{3 / 2}$ peak and its satellite at 786 and $792 \mathrm{eV}$, respectively. These $6 \mathrm{eV}$ differences between the Co 2 p peaks and their satellites suggests the presence of $\mathrm{Co}(+\mathrm{II})$ ions on the foam's surface. ${ }^{44}$ We thus most probably obtain amorphous Co particles with $\mathrm{Co}(+\mathrm{II})$ ions on the surface. 


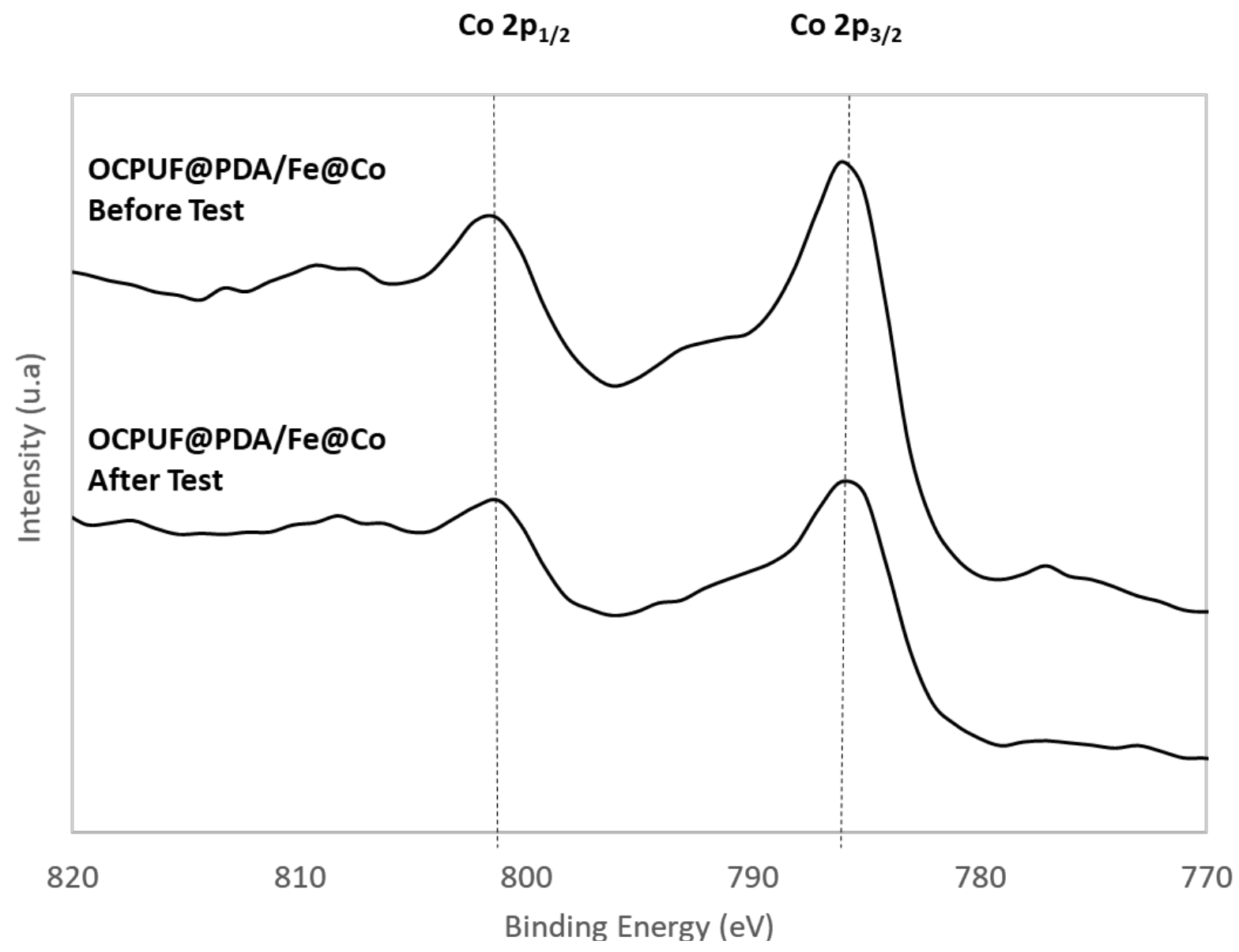

Figure 6. Cobalt 2p XPS spectra of OCPUF@PDA(TRIS)/Fe@Co before and after 6 catalytic runs.

In the open literature, the synthesis of cobalt particles from a cobalt salt and $\mathrm{NaBH}_{4}$ as reducing agent at room temperature indeed leads to amorphous cobalt phase, as shown by the XRD patterns of as-synthesized cobalt particles, which often present a broad band centered at $2 \theta=45^{\circ}$ before thermal treatment $\left(200-500{ }^{\circ} \mathrm{C}\right) .{ }^{43,45,46}$ From TEM analysis, Netskina and co-authors described the structure of cobalt nanoparticles as a cobalt boron core surrounded by an oxide layer. ${ }^{46}$ The $\mathrm{pH}$ could also influence the nature of the formed cobalt phase. In our conditions, we used a $0.1 \mathrm{M} \mathrm{NaBH}_{4}$ aqueous solution at an operating $\mathrm{pH}$ around 10 . In these conditions, cobaltous hydroxide $\mathrm{Co}(\mathrm{OH})_{2}$ particles might form according to the potential-pH equilibrium diagram of cobalt-water system reported by Huang and co-autors. ${ }^{47}$ In agreement, Liu and $\mathrm{Li}$ identified $\mathrm{Co}(\mathrm{OH})_{2}$ as an intermediate for the synthesis of fine $\mathrm{CoB}$ nanoparticles whom precipitation is favoured by increasing $\mathrm{NaOH}$ concentrations. ${ }^{32}$. 


\subsection{Hydrolysis of an unstable $0.1 \mathrm{M}$ solution of $\mathrm{NaBH}_{4}$ at $20^{\circ} \mathrm{C}$}

This section reports the catalytic results obtained for the hydrolysis of a $0.1 \mathrm{M} \mathrm{NaBH}_{4}$ solution prepared from a $\mathrm{NaBH}_{4}$ powder $(>98 \%)$ and purified water $(0.15 \mathrm{~g})$ at $20^{\circ} \mathrm{C}$ and $\mathrm{pH}$ 9-10. Figure 7 shows the volume of produced $\mathrm{H}_{2}\left(\mathrm{VH}_{2}\right)$ versus time for the hydrolysis of $\mathrm{NaBH}_{4}$ in the presence of pristine OCPUF, PDA $\left(\mathrm{NaIO}_{4}\right) / \mathrm{Fe}$ powder, OCPUF@PDA $\left(\mathrm{NaIO}_{4}\right) / \mathrm{Fe}$, and OCPUF@PDA $\left(\mathrm{NaIO}_{4}\right) / \mathrm{Fe} @ \mathrm{Co}$, as well as in the absence of a foam or reagent (blank).

$\mathrm{NaBH}_{4}$ powder dissolved in water at $\mathrm{pH}$ 9-10 hydrolyses spontaneously, as confirmed by the blank curve (Figure 7). The superimposition of the OCPUF and blank curves clearly shows that OCPUF is totally inert. In contrast, both PDA( $\left(\mathrm{NaIO}_{4}\right) / \mathrm{Fe}$ and OCPUF@PDA( $\left(\mathrm{NaIO}_{4}\right) / \mathrm{Fe}$ present an apparent catalytic activity. These results tend to show that polydopamine itself catalyses the hydrolysis of $\mathrm{NaBH}_{4}$. According to the open literature, a probable catalytic effect of PDA itself could indeed well result from a redox mediator role of PDA in the hydrolysis reaction, ${ }^{41,48-50}$ as well as from the formation of catecholborane groups on PDA that could also release $\mathrm{H}_{2} \cdot{ }^{42}$ A minor role of PDA-complexed Fe can, however, not be excluded.

It can be seen that free PDA $\left(\mathrm{NaIO}_{4}\right) / \mathrm{Fe}$ particles are more active than OCPUF-supported $\mathrm{PDA}\left(\mathrm{NaIO}_{4}\right) / \mathrm{Fe}$ for a same mass of PDA $\left(\mathrm{NaIO}_{4}\right) / \mathrm{Fe}$ (see Table 1). The higher number of available active sites with a $\mathrm{PDA}\left(\mathrm{NaIO}_{4}\right) / \mathrm{Fe}$ powder compared to supported $\mathrm{PDA}\left(\mathrm{NaIO}_{4}\right) / \mathrm{Fe}$ can explain this result. However, the main advantage of using OCPUF@PDA $\left(\mathrm{NaIO}_{4}\right) / \mathrm{Fe}$ is its easy recyclability compared to a powder, as illustrated by the almost constant activity observed over three runs (see for instance OCPUF@PDA( $\left(\mathrm{NaIO}_{4}\right) / \mathrm{Fe}$ Run 2 and Run 3, Figure 7). The slight activity decrease observed between first and second runs is essentially due to $\mathrm{PDA}\left(\mathrm{NaIO}_{4}\right) / \mathrm{Fe}$ leaching. Indeed, from the weighing of the foam after each use, the PDA mass loss was estimated to be $9.64 \mathrm{mg}$ after the first run and $3.49 \mathrm{mg}$ after the second run. Finally, OCPUF@PDA $\left(\mathrm{NaIO}_{4}\right) / \mathrm{Fe} @ \mathrm{Co}$ has a higher activity compared to OCPUF@PDA(NaIO 4$) / F e$, and thus confirms the expected catalytic effect of cobalt particles. 


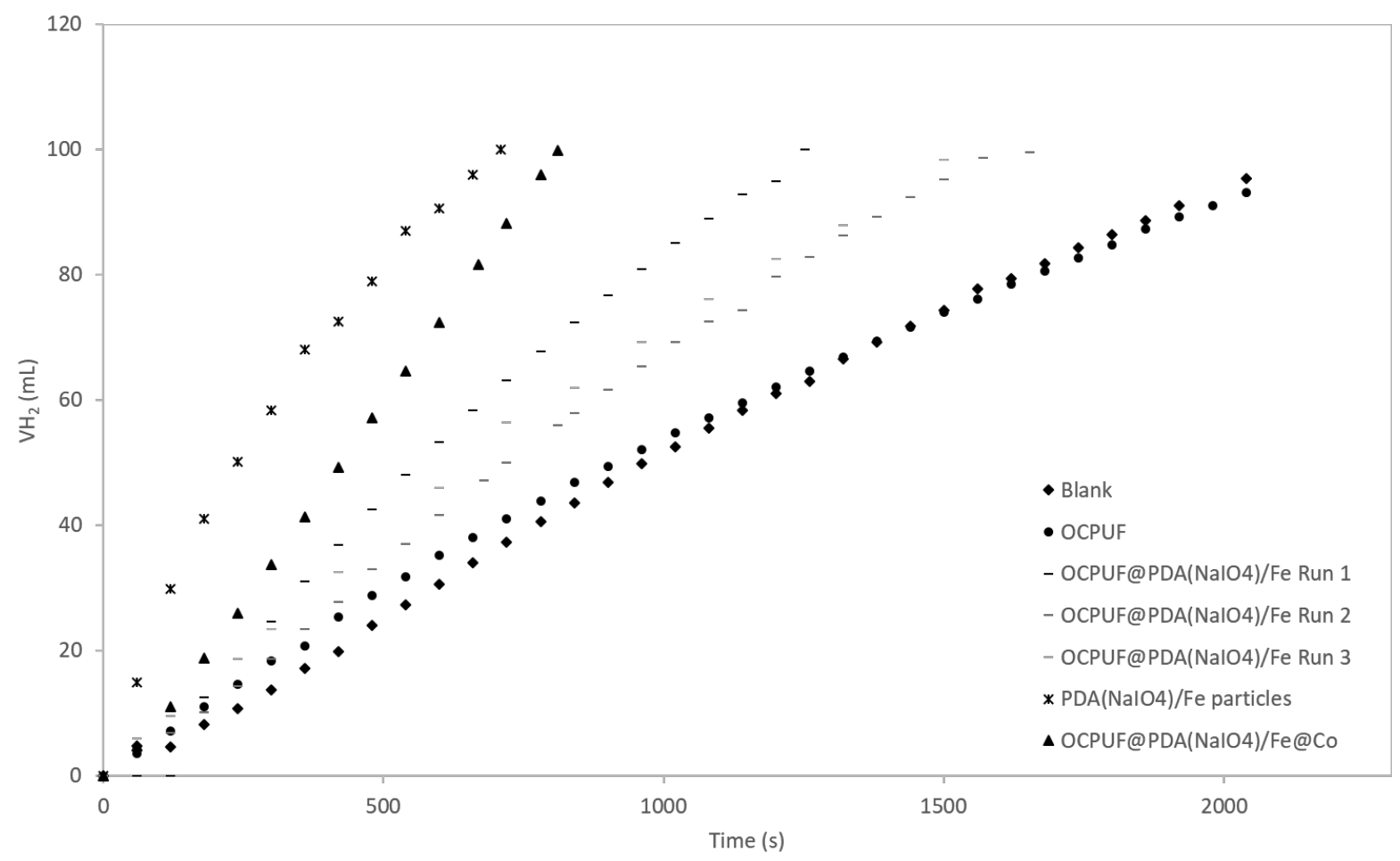

Figure 7. Cumulated volumetric $\mathrm{H}_{2}$ production by the spontaneous hydrolysis of $\mathrm{NaBH}_{4}(0.1$ M) (blank), and in the presence of OCPUF (204.08 mg), OCPUF@PDA( $\left(\mathrm{NaIO}_{4}\right) / \mathrm{Fe}$ (composed of $200.57 \mathrm{mg}$ of OCPUF coated with $64.13 \mathrm{mg}$ of polydopamine), PDA $\left(\mathrm{NaIO}_{4}\right) / \mathrm{Fe}(64 \mathrm{mg})$ and OCPUF@PDA(NaIO 4$) / \mathrm{Fe} @ \mathrm{Co}$ (composed of $172.87 \mathrm{mg}$ of OCPUF coated with $14.55 \mathrm{mg}$ of polydopamine and $5.34 \mathrm{mg}$ of cobalt) at $20^{\circ} \mathrm{C}$.

\subsection{Hydrolysis of an alkaline Redubore2020@ $\mathrm{NaBH}_{4}$ stable solution at $20{ }^{\circ} \mathrm{C}$}

The commercial solution Redubore2020 (C) used in this section as a source of $\mathrm{NaBH}_{4}$ was purchased from $\mathrm{H} \& \mathrm{~V}$ Chemicals (Vilvoorde, Belgium). The solution is a $\mathrm{NaOH}$-stabilised aqueous solution of $\mathrm{NaBH}_{4}$ composed of 20 wt.\% $( \pm 0.5$ wt. $\%) \mathrm{NaBH}_{4}$ and 20 wt.\% $( \pm 2.0$ wt.\%) $\mathrm{NaOH}$. This section reports the catalytic results obtained for the hydrolysis of a $0.1 \mathrm{M}$ $\mathrm{NaBH}_{4}$ solution at $20{ }^{\circ} \mathrm{C}\left( \pm 0.6{ }^{\circ} \mathrm{C}\right)$ prepared from Redubore2020 C $(2.4 \mathrm{~mL})$ and purified water $(150 \mathrm{~mL})$ at $\mathrm{pH} 13.2( \pm 0.1)$.

Figure 8 shows the results for the production of $\mathrm{H}_{2}$ from this solution in the presence of a OCPUF@PDA(TRIS)/Fe or OCPUF@PDA(NaIO 4$) / \mathrm{Fe}$ foam, and in the presence of a OCPUF@PDA(NaIO $\left.{ }_{4}\right) / \mathrm{Fe} @$ Co or OCPUF@PDA(TRIS)/Fe@Co foam, as well as in the absence of a foam (blank). As expected, under these conditions (i.e.: in a highly alkaline solution $-\mathrm{pH} 13$ ), there is no spontaneous $\mathrm{H}_{2}$ release. In addition, no reaction was observed 
in the presence $\mathrm{PDA}\left(\mathrm{NaIO}_{4}\right) / \mathrm{Fe}$ particles, OCPUF@PDA $\left(\mathrm{NaIO}_{4}\right) / \mathrm{Fe}$ or OCPUF@PDA(TRIS)/Fe in contrast to what was observed at pH $9-10$ with a $0.1 \mathrm{M} \mathrm{NaBH}_{4}$ solution prepared from a high purity powder. Thus, in these conditions, it is clear that the observed $\mathrm{NaBH}_{4} \quad$ hydrolysis with OCPUF@PDA(NaIO 4$) / \mathrm{Fe} @ \mathrm{Co}$ and OCPUF@PDA(TRIS)/Fe@Co is only due to the presence of the cobalt catalytic phase on the foam's surface. In other words, no catalytic activity due to PDA and/or Fe can be observed in this case.
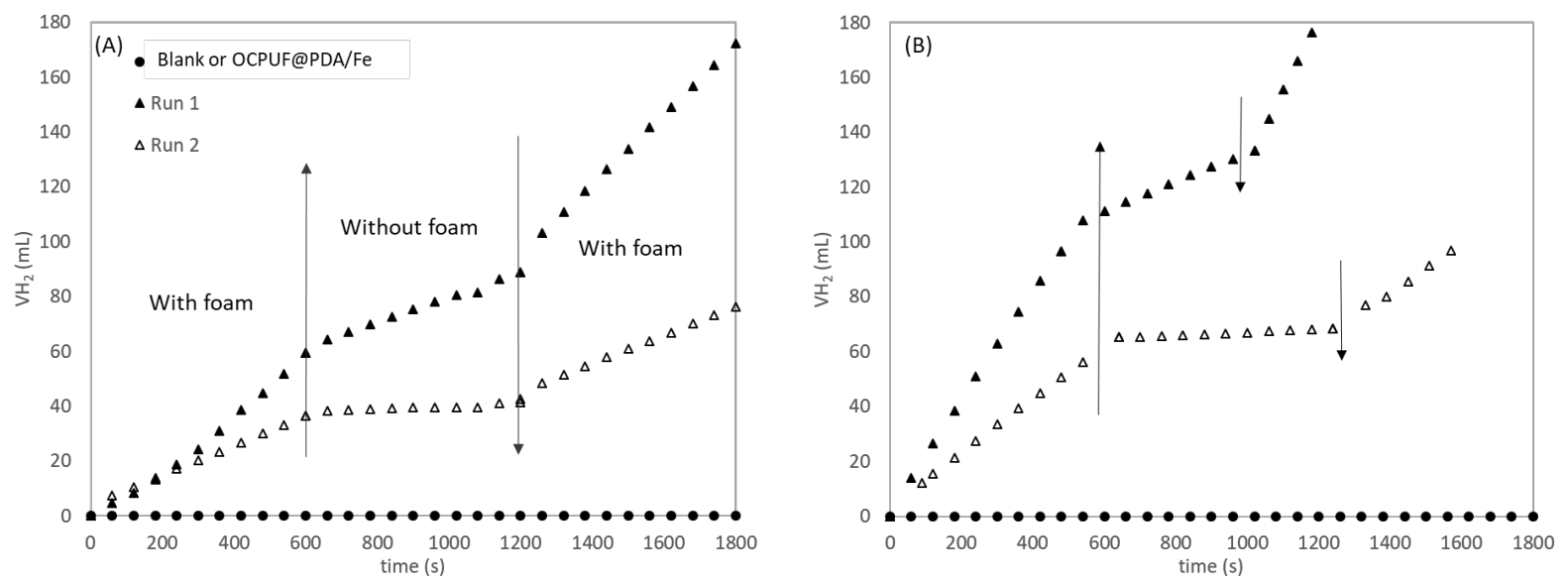

Figure 8. Cumulated volumetric $\mathrm{H}_{2}$ production versus time and "stop and go" tests in the absence of a foam or in the presence of (A) an OCPUF@PDA( $\left(\mathrm{NaIO}_{4}\right) / \mathrm{Fe}$ or (B) OCPUF@PDA(TRIS)/Fe foam (black dots), and for the two first runs in the presence of (A) OCPUF@PDA(NaIO 4 )/Fe@Co or (B) OCPUF@PDA(TRIS)/Fe@Co (triangles).

The long-term stability of our catalytic foams OCPUF@PDA( $\left(\mathrm{NaIO}_{4}\right) / \mathrm{Fe} @ \mathrm{Co}$ and OCPUF@PDA(TRIS)/Fe@Co in these alkaline conditions was next investigated by measuring the $\mathrm{H}_{2}$ production rate in their presence for 6 successive runs. From run 1 to 5 , the foams were pulled out of the reaction medium after each run, rinsed with distilled water and put back in a fresh $0.1 \mathrm{M}$ Redubore2020 (C) solution. To check if a longer exposure to air could cause deactivation, the foams were pulled out of the reaction medium, washed with deionised water and dried at room temperature overnight before run 6 . In addition, during the two first runs, the leaching of active particles was evaluated by the "stop and go" experiments presented in Figure 8. The latter consisted in measuring the $\mathrm{H}_{2}$ production rate while the foams were removed temporarily from the reaction solutions (upwards pointing arrows). Assuming a constant activity and measuring the reaction rate, the extent of Co leaching can thus be estimated. The foams were finally reintroduced into the solution (downwards pointing 
arrows) in order to measure the recovered activity. These experiments revealed a strong leaching of active Co particles during the first run for both OCPUF@PDA(NaIO 4$) / \mathrm{Fe} @ \mathrm{Co}$ and OCPUF@PDA(TRIS)/Fe@Co samples. These results can explain the important activity drop observed between Run 1 and Run 2. Satisfyingly however, the leaching was negligible in the second run for both types of catalytic foams.

Figure 9 shows the normalised catalytic activity for the runs 1-6, i.e. the ratio between the apparent rate of each run and the rate of the first run. Globally, the activity decreases with the number of reuses for both foams (see dots and triangles in Figure 9), but the activity loss is more drastic for OCPUF@PDA $\left(\mathrm{NaIO}_{4}\right) / \mathrm{Fe} @ \mathrm{Co}$. Indeed, a continuous decrease of activity can be observed with the latter until it stops (run 6), whereas a stabilisation of the activity is observed after run 5 for OCPUF@PDA(TRIS)/Fe@Co. These results suggest a higher Co leaching with OCPUF@PDA $\left(\mathrm{NaIO}_{4}\right) / \mathrm{Fe} @ \mathrm{Co}$, which most probably results from the weaker stability of the PDA coating when it is prepared with $\mathrm{NaIO}_{4}$ as oxidant. This is confirmed by the coloration of the reaction medium after runs 1 to 3 with both catalytic foams (Figure 10). Consequently, only OCPUF@PDA(TRIS)/Fe@Co samples will be considered in the following section.

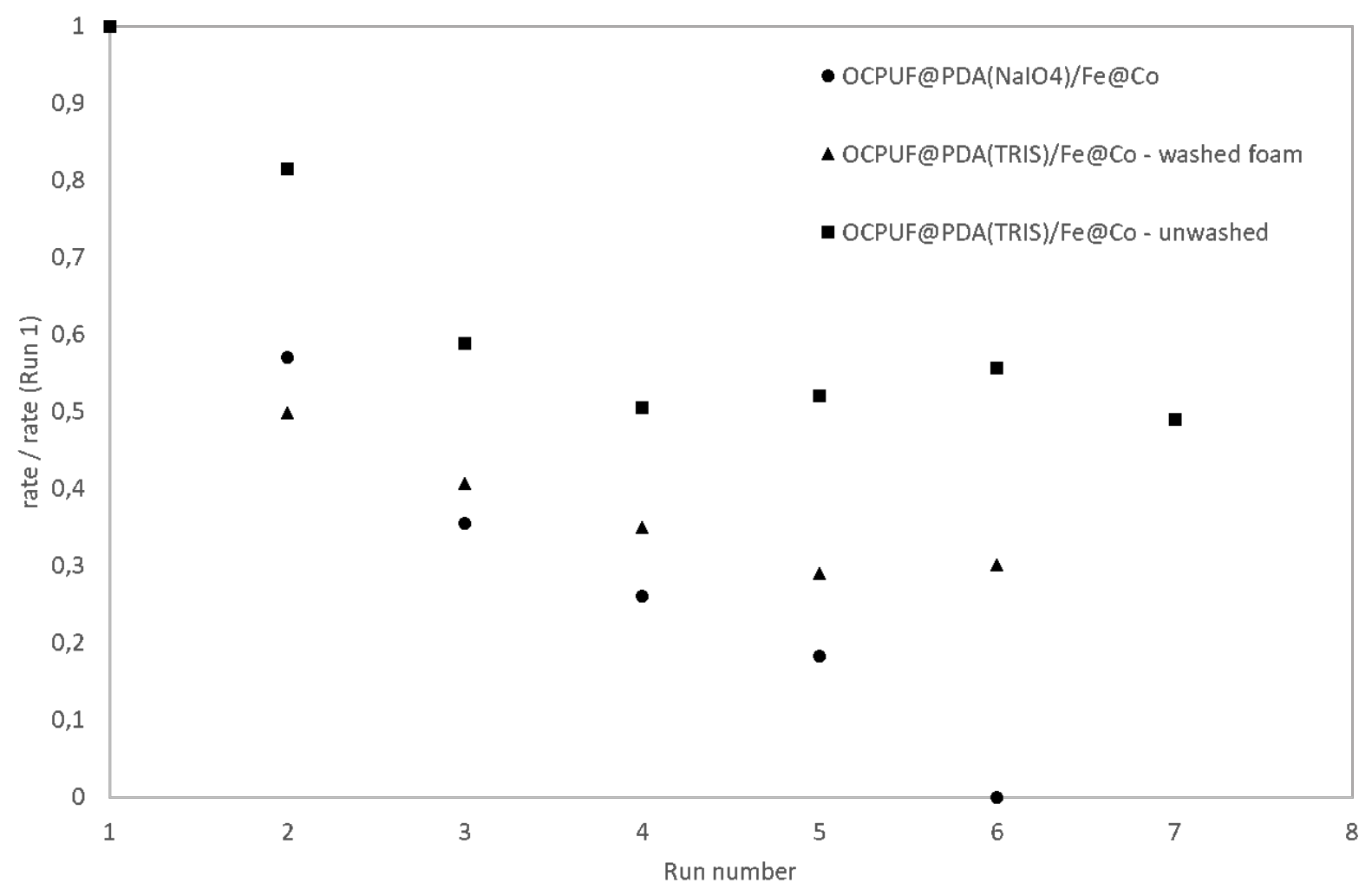

Figure 9. Normalised rates for 6 consecutive runs in the presence of OCPUF@PDA(NaIO4)/Fe@Co (dots) or OCPUF@PDA(TRIS)/Fe@Co (triangles) washed between each runs, and of OCPUF@PDA(TRIS)/Fe@Co (squares) unwashed between each 
runs. Normalised rate for the run 7 performed in the presence of unwashed OCPUF@PDA(TRIS)/Fe@Co after one week of storage at room temperature.

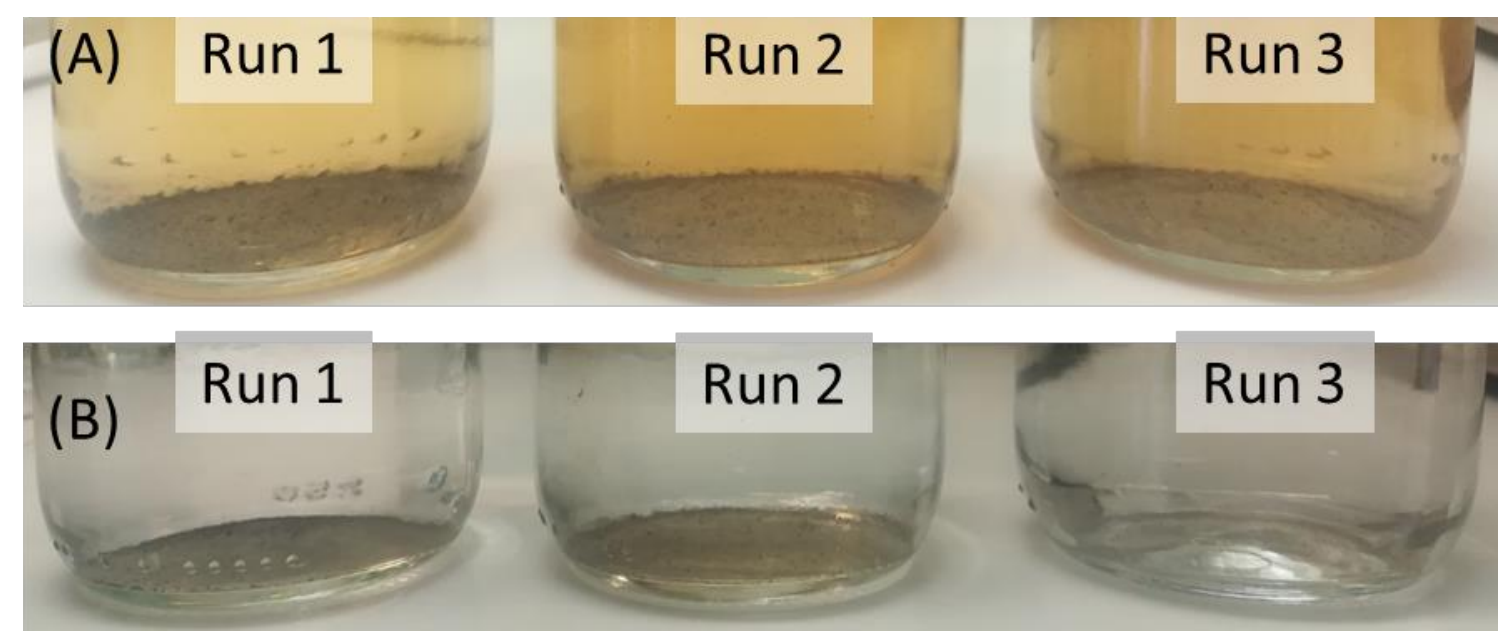

Figure 10. Colour of the reaction medium after $\mathrm{NaBH}_{4}$ hydrolysis under alkaline conditions for the 3 first runs with washed (A) OCPUF@PDA $\left(\mathrm{NaIO}_{4}\right) / \mathrm{Fe} @ \mathrm{Co}$ and (B) OCPUF@PDA(TRIS)/Fe@Co.

\subsection{Co deactivation investigation and process optimisation}

If we assume that no significant leaching occurs anymore after Run 2 in the case of OCPUF@PDA(TRIS)/Fe@Co foams in agreement with the stop and go experiment presented in Figure 8, the activity loss should then be essentially due to cobalt deactivation. In 2017, Paladini and co-workers reported their work about cobalt deactivation in low and highly concentrated alkaline $(\mathrm{NaOH})$ solutions of $\mathrm{NaBH}_{4}$ at room temperature. ${ }^{51}$ Their results highlighted a "peeling-off" cobalt deactivation mechanism based on the formation of a cobalt oxides' layer after contact with an aqueous solution, i.e.: during the washing of the catalyst solid phase. These oxidised cobalt species are not stable under strongly reducing conditions and thus can leach during further exposure to $\mathrm{NaBH}_{4}$ solutions. Inspired by this work, we studied the effect of the absence of washings on our cobalt-doped foam OCPUF@PDA(TRIS)/Fe@Co between each catalytic run. The latter was thus tested for the hydrolysis of a $0.1 \mathrm{M}$ alkaline $\mathrm{NaBH}_{4}$ solution under similar conditions than those described above for 6 runs, but without a washing step between each runs. As can be seen in Figure 9 the apparent activity stayed stable after the third run in the absence of washings, whereas it took 5 runs to stabilize when the catalytic foam was washed between the runs. Moreover, the 
washed foam maintained only around $30 \%$ of its initial activity whereas the unwashed foam kept about $50 \%$ of its initial activity, and this even after one-week storage at room temperature (run 7). According to the litterature, ${ }^{51}$ these results tend to confirm that the active cobalt phase is deactivated by exposure to water between each run.

ICP-AES elemental analyses were performed on both the washed and unwashed OCPUF@PDA(TRIS)/Fe@Co foams at the end of each run, in order to valid or invalid this assumption (Table 1).

Table 1. Mass of cobalt on OCPUF@PDA(TRIS)/Fe@Co foams before/after the recycling test estimated or measured by ICP-AES analysis.

\begin{tabular}{|c|c|c|c|c|}
\hline & \multicolumn{4}{|c|}{ OCPUF@PDA(TRIS)/Fe@Co foams } \\
\hline & m $_{\text {ICP·init }}{ }^{a}(\mathrm{mg})$ & $a_{\text {init }}{ }^{b} \times 10^{6}(\mathrm{~mol} / \mathrm{s} / \mathrm{mg})$ & $\mathbf{m}_{\text {estimated.end }}{ }^{\mathbf{c}}$ (mg) & $\mathrm{m}_{\text {ICP.end }}{ }^{\mathrm{d}}$ (mg) \\
\hline With washings & 4.47 & 1.84 & 1.30 & 3.99 \\
\hline Without washings & 6.98 & 0.83 & 3.75 & 3.64 \\
\hline
\end{tabular}

${ }^{\mathrm{t}, \mathrm{d}} \mathrm{m}_{\mathrm{ICP} \cdot \mathrm{init}}$ and $\mathrm{m}_{\mathrm{ICP} \text {.end }}$ are the measured mass (by ICP-AES) of Co on each foam before and after the recycling test, respectively (run6).

${ }^{\mathrm{J}} \mathrm{a}_{\text {init }}$ is the initial apparent activity during Run 1 calculated from the measured Co mass on the foam before the test and the initial reaction rate during Run 1.

' $\mathrm{m}_{\text {estimated.end_ }}$ is the estimated final mass of Co on the foam after the last run (run6). The estimated value is obtained from the last measured reaction rate and considering a constant apparent activity (ie, $a_{\text {init }}=\mathrm{cst}$ ).

The estimated ( $m_{\text {estim.end }}$ ) and measured (mICP.end) values of cobalt content of the unwashed foam at the end of the recycling experiments are very close to each other ( $3.75 \mathrm{vs} .3 .64 \mathrm{mg}$ ). This shows that all Co particles on the unwashed foam's surface are active at the end of the recycling tests. In agreement with the apparent activity for the unwashed foam presented in Figure 9, the ICP measurements before ( $\left.\mathrm{m}_{\mathrm{ICP} \text {.init }}\right)$ and after the tests (mICP.end) confirm that $c a$. $50 \%$ of Co particles are leaching during the two first runs. Thus, the loss activity for the unwashed foam is not due to a deactivation process but to a Co leaching phenomenon during the first runs. From the total cobalt content measured by ICP analysis, the turnover frequency (TOF) of the unwashed OCPUF@PDA(TRIS)/Fe@Co foam is estimated to be $0.013 \mathrm{~h}^{-1}$ in average between run 3 and run 7 .

In contrast, for the washed foam, the estimated ( $\mathrm{m}_{\text {estim.end }}$ ) and measured ( $\left.\mathrm{m}_{\mathrm{ICP} . \mathrm{end}}\right)$ values of the cobalt content at the end of the recycling experiments are very far from each other $(1.30$ vs. $3.99 \mathrm{mg}$ ). These results demonstrate that only about $33 \%$ the cobalt present on the surface of the foam is active. This is in accordance with the measured apparent activity for the washed OCPUF@PDA(TRIS)/Fe@Co foam in the run 6, which was found to be around 30\% 
of the initial activity (Figure 9). In addition, the ICP measurements before ( $\mathrm{m}_{\mathrm{ICP} \text {.nit }}$ ) and after (mICP.end) test show that approximately $11 \%$ of the Co particles were lost during the two first runs ( 4.47 vs $3.99 \mathrm{mg}$ ) in this case. These measures confirm that the deactivation process is of the first order for the washed foam.

The deactivation of the cobalt active phase observed during the washing steps was next investigated by recording the Co 2p XPS spectrum of the OCPUF@PDA(TRIS)/Fe@Co foam after the catalytic tests and comparing it to that recorded before. The obtained spectrum (Figure 6, bottom) is remarkably similar to that recorded before (Figure 6, top), with a $6 \mathrm{eV}$ difference between the Co $2 \mathrm{p}_{3 / 2}$ and Co2 $\mathrm{p}_{1 / 2}$ peaks and their satellites, therefore discarding a possible change of valence state of the Co particles as a possible deactivation path.

The 1 mm scale SEM picture of OCPUF@PDA(TRIS)/Fe@Co presented in Figure 11C shows that the coating on the foam's surface after 6 uses with washing treatments between each run looks similar to that observed before use (Figure 5B). Higher magnification SEM images shown in Figure 11D reveal the presence of cobalt micro-sponges that also look similar to those observed before test - a little more dispersed though due to the cobalt leaching (Figure 5D). As a control experiment, pristine OCPUF was immersed in a $\mathrm{NaBH}_{4}$ Redobore2020 solution $(0.1 \mathrm{M})$ at room temperature for $1 \mathrm{~h}$. The SEM observations of the foam before (Figure 3A,D) and after (Figure 11A,B) exposure to the Redubore2020 alkaline solution shows that no modification of the support occurs in these conditions. Finally, the EDX analysis of the washed OCPUF@PDA(TRIS)/Fe@Co after 6 catalytic runs presented in Figure 11E confirms that cobalt is still present.

Thus, we can state, that the washing steps play an important role in the decrease of the apparent catalytic activity. However, no significant changes in the active phase oxidation state and/or particle morphology can be observed, and no clear conclusions can be drawn concerning the observed deactivation process with the washed foams. 

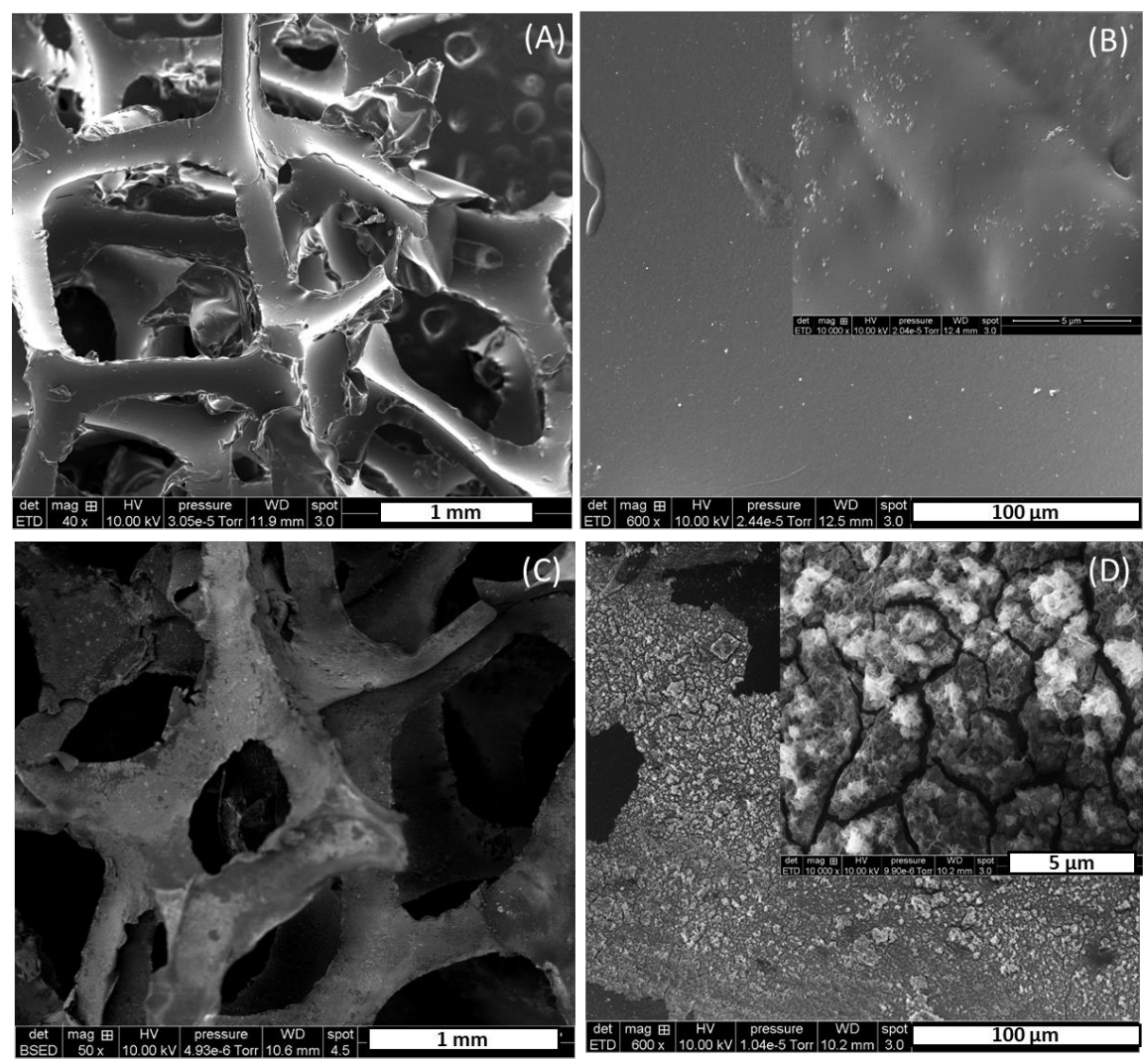

(B)
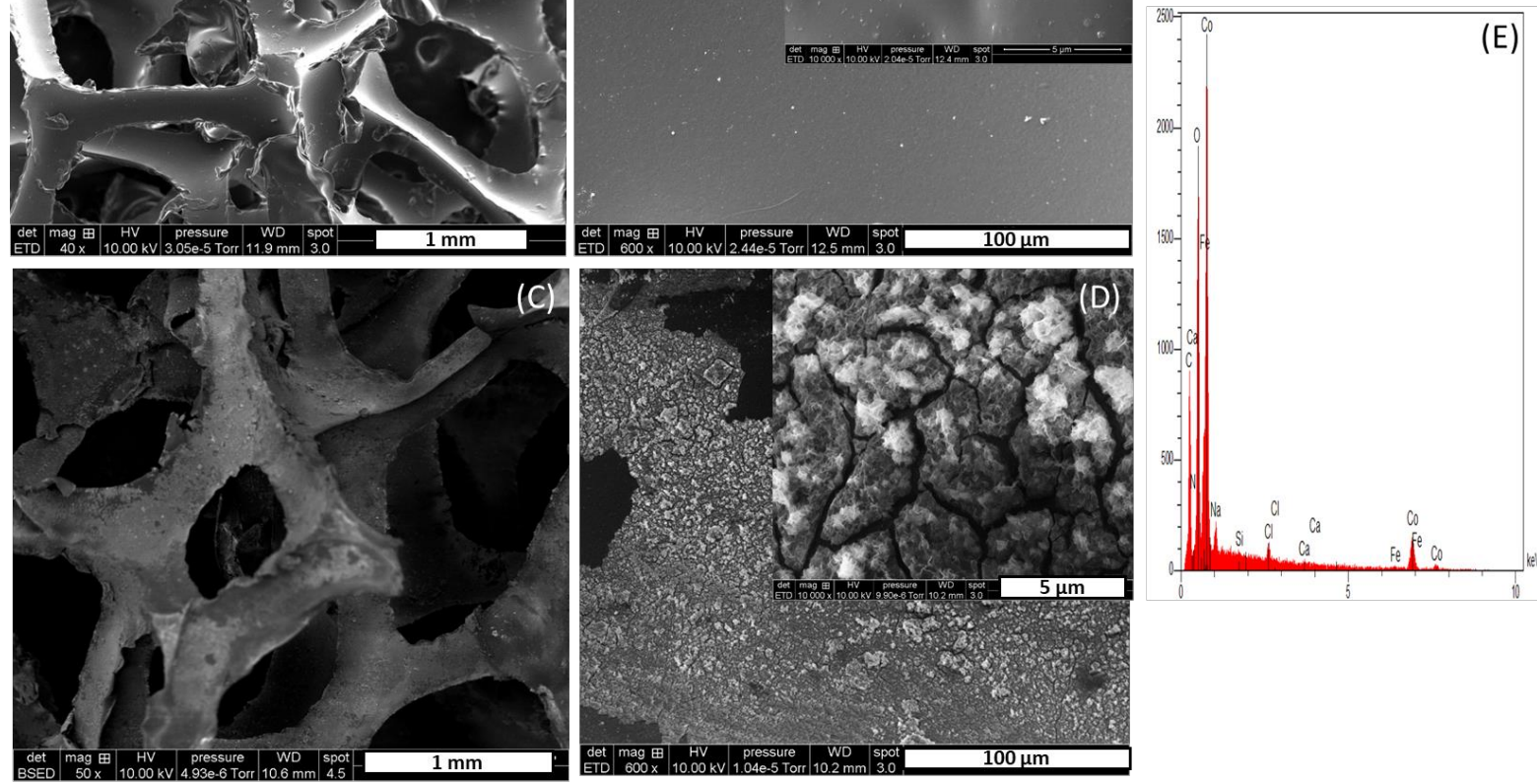

Figure 11. (A) Low and (B) High magnification SEM pictures of OCPUF after exposure to a $\mathrm{NaBH}_{4}$ Redubore2020 solution (0.1 M, pH 13) at room temperature. (C) Low and (D) High magnification SEM pictures of washed OCPUF@PDA(TRIS)/Fe@Co after 6 catalytic runs. (E) EDX spectrum of OCPUF@PDA(TRIS)/Fe@Co after 6 catalytic runs.

\subsection{Estimation of the apparent activation energy and discussion of possible applications}

In this part, the results obtained for the estimation of the apparent activation energy are presented and discussed. The kinetics of $\mathrm{NaBH}_{4}$ hydrolysis is a complex process since it is influenced by many factors: operating temperature, $\mathrm{NaBH}_{4}$ concentration, catalyst performances, time span and $\mathrm{pH}$ (i.e.: $\mathrm{NaOH}$ concentration). ${ }^{11,25,52}$ Furthermore, the metaborate by-products $\left(\mathrm{NaBO}_{2} \cdot x \mathrm{H}_{2} \mathrm{O}\right)$ will increase the $\mathrm{pH}$ during the reaction and inhibit the production of $\mathrm{H}_{2}$ even if the reaction is strongly thermodynamically favoured. The $\mathrm{NaBH}_{4}$ hydrolysis mechanism has been largely studied and many kinetic models have been proposed, as shown in Table 2. However, both the kinetic and reaction mechanism still remain unsolved. Given the complexity of the reaction, this paper only focuses on a simple estimation of the kinetic parameters. In our conditions, a constant rate is measured from the experimental cumulated volumetric $\mathrm{H}_{2}$ production versus time (i.e. $\mathrm{dnH}_{2} / \mathrm{dt}=$ constant). Thus, according to Holbrook and Twist for the hydrolysis of $\mathrm{BH}_{4}^{-}$catalysed by metal-boron 
alloys,${ }^{53}$ the apparent reaction rate can be easily calculated assuming a zero order kinetic for $\mathrm{NaBH}_{4}$ hydrolysis. The apparent activation energy Ea app of OCPUF@PDA(TRIS)/Fe@Co is estimated from the Arrhenius relationship. For that purpose, the activity of the stable catalytic sample, OCPUF@PDA(TRIS)/Fe@Co after run 6, was measured at different temperatures (2 to $40{ }^{\circ} \mathrm{C}$ ) under otherwise similar reaction conditions (Redubore $2020 \mathrm{C}, 0.1 \mathrm{M}, 150 \mathrm{~mL}$, without washing steps, Figure 12A). The resulting Arrhenius curve is presented in Figure 12B. The apparent activation energy found for this catalytic system under these operating conditions is $25.5 \mathrm{~kJ} \cdot \mathrm{mol}^{-1}$. By comparing the results obtained with those of previously reported studies (Table 2), the estimated activation energy of OCPUF@PDA(TRIS)/Fe@Co is one of the lowest. It is close to that reported for $\mathrm{CoCl}_{2}$, which corroborates the results obtained by XPS analysis revealing the presence of $\mathrm{Co}(+\mathrm{II})$ ions on the foam's surface. Thus, it can be stated that our $\mathrm{S}_{2} \mathrm{CS}$ are interesting candidates for the carbon-free production of $\mathrm{H}_{2}$ at room temperature from a stable solution of $\mathrm{NaBH}_{4}$.

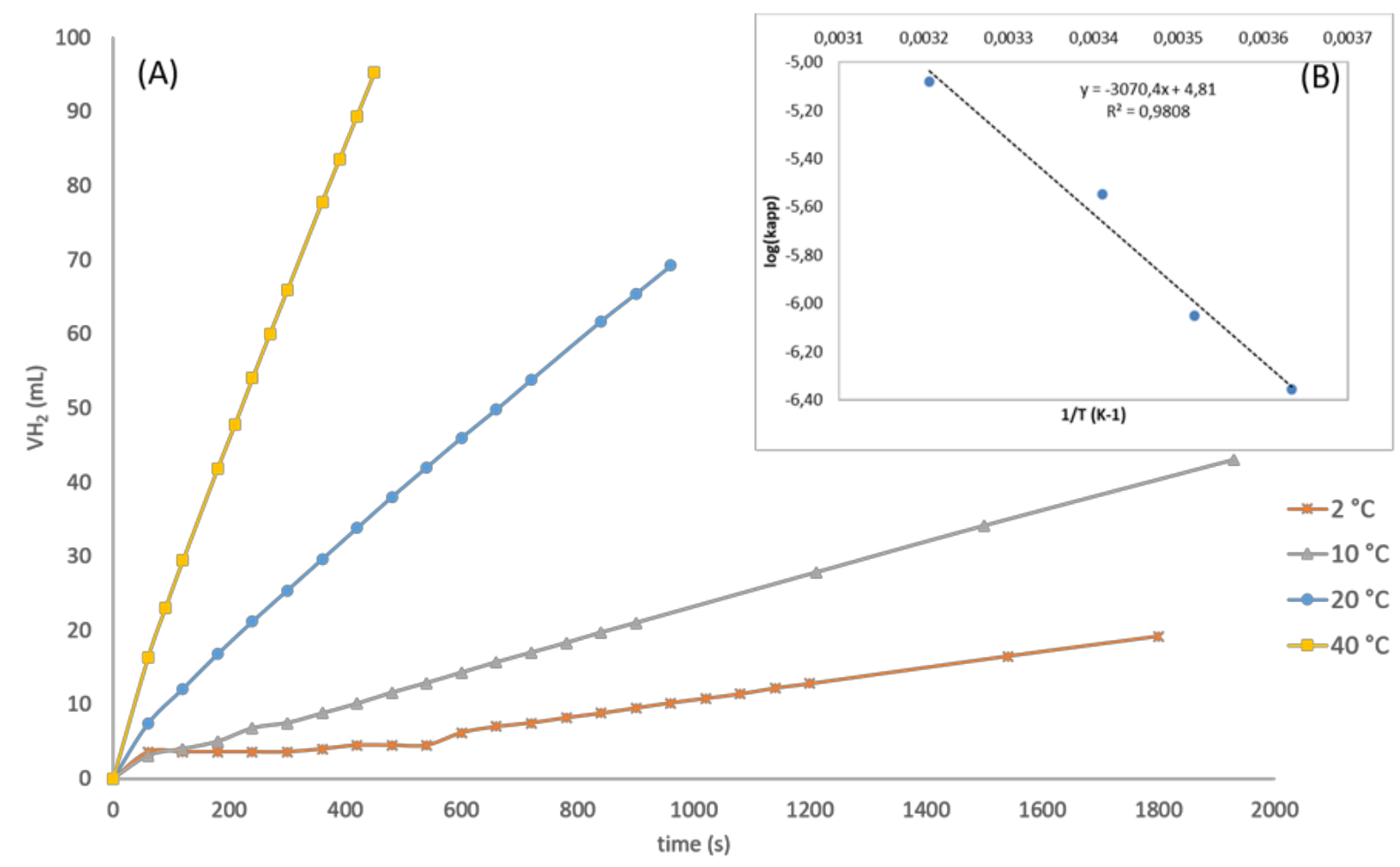

Figure 12. (A) $\mathrm{H}_{2}$ generation rate for the hydrolysis of $\mathrm{NaBH}_{4}$ from $0.1 \mathrm{M}$ Redubore 2020C solutions in the presence of OCPUF@PDA(TRIS)/Fe@Co at 2, 10, 20 and $40{ }^{\circ} \mathrm{C}$ without washing steps (respectively runs 8, 9, 7 and 10). (B) Arrhenius plot. 
Table 3 gives a view of the $\mathrm{H}_{2}$ production rate recorded with another Co decorated polydopamine catalyst. The $\mathrm{H}_{2}$ Generation Rate (HGR) of OCPUF@PDA(TRIS)/Fe@Co is $76.4 \pm 3.2 \mathrm{~L} \cdot \mathrm{h}^{-1} \cdot \mathrm{g}_{\mathrm{cat}}{ }^{-1}$ at $20{ }^{\circ} \mathrm{C}$ from run 3 to 7 (stable catalytic activity). The reported production rate with cobalt on PDA-coated carbon nanotubes ("Co/Pdop-o-MWCNT") is more than 2 times faster. However, it is important to note that this high HGR was obtained from a non-stable hydride solution, i.e.: pure $\mathrm{NH}_{3} \mathrm{BH}_{3}$ at high concentration in water. Moreover, the authors have worked with a catalytic powder, which is not compatible with possible process development. It is well known that catalytic powders exhibit a higher activity, thanks to a more important specific surface area, and that the production rate will be more important with an unstable hydride solution (see Figure 7).

In contrast, the present work focused on the hydrolysis of a stable hydride solution with a supported bio-inspired catalyst, which facilitates the stock, load and recyclability operations. The gravimetric hydrogen storage capacity (GHSC) and the $\mathrm{H}_{2}$ volumetric density of the presented system $\left(\mathrm{NaBH}_{4}-\mathrm{NaOH}-\mathrm{H}_{2} \mathrm{O}\right)$ are 0.04 wt. $\% \mathrm{H}_{2}$ and $0.39 \mathrm{~kg} \mathrm{H} / \mathrm{m}^{3}$, respectively. The $\mathrm{H}_{2}$ storage capacity is very weak in these conditions. Indeed, the volumetric density is 10 times below that of 700 bar pressurized $\mathrm{H}_{2}$ gas. However, high-pressurized $\mathrm{H}_{2}$ gas can cause safety issues, in particular for a portable process. Pure $\mathrm{NaBH}_{4}$ presents high GHSC and volume density (i.e. 10.6 wt. $\% \mathrm{H}_{2}$ and $113.4 \mathrm{~kg} \mathrm{H} / \mathrm{m}^{3}$ respectively), but it is not possible to use it in this form for portable $\mathrm{H}_{2}$ storage solutions. Consequently, the system proposed in this work: $\mathrm{NaBH}_{4}-\mathrm{NaOH}-\mathrm{H}_{2} \mathrm{O}$ and the bio-inspired catalytic tool, OCPUF@PDA(TRIS)/Fe@Co, combine a good stability toward spontaneous hydrolysis ${ }^{54,55}$ with correct HGR for a portable power system. 
Table 2. Summary of published kinetic models for Co-catalysed hydrolysis of $\mathrm{NaBH}_{4}$.

\begin{tabular}{|c|c|c|c|c|c|c|c|c|}
\hline Catalyst & $\begin{array}{l}\mathrm{NaBH}_{4} \\
\text { (wt\%) }\end{array}$ & $\begin{array}{l}\mathrm{NaOH} \\
(\mathrm{wt} \%)\end{array}$ & $\begin{array}{l}\text { Temperature } \\
\text { range }\left({ }^{\circ} \mathbf{C}\right)\end{array}$ & $\begin{array}{l}\mathrm{NaBH}_{4} \\
\text { order }\end{array}$ & Co order & $\begin{array}{l}E a_{a p p} \\
(\mathrm{~kJ} / \mathrm{mol})\end{array}$ & $\begin{array}{l}\text { HGR } \\
\left(\mathrm{L} \cdot \mathrm{h}^{-1} \cdot \mathrm{g}_{\mathrm{cat}}{ }^{-1}\right)\end{array}$ & Refs. \\
\hline Co & 0.9 & 10 & $10-50$ & 0 & - & 41.9 & 7.57 & 53 \\
\hline Raney Co & 0.9 & 10 & $10-30$ & 0 & - & 53.7 & 16.05 & 53 \\
\hline Co-P & 5 & 1 & $30-45$ & 0 & - & 48.1 & 110.76 & 54 \\
\hline Co-B & 20 & 5 & $10-30$ & 0 & - & 64.9 & 165 & 33 \\
\hline Co-B-C & 0.7 & 4 & $25-40$ & 0 & - & 57.8 & 76.09 & 55 \\
\hline Co@C $\mathrm{C}^{\mathrm{a}}$ & 5 & 2 & 30 & 1 & 1.17 & 45.0 & 100.8 & 56 \\
\hline $\mathrm{Co}-\gamma \mathrm{Al}_{2} \mathrm{O}_{3}$ & 5 & 5 & $30-50$ & 0 & - & 32.6 & 13.2 & 57 \\
\hline $\mathrm{Co}^{0}$ nanoclusters & 0.58 & 2 & $20-40$ & 0 & 1 & 39.0 & 514.29 & 58 \\
\hline $\mathrm{Co}^{0}$ nanoparticles & 19 & 0 & $40-80$ & 0 & 1 & 35.0 & 63.6 & 35 \\
\hline $\mathrm{CoCl}_{2}$ & $0.5-2$ & 0.04 & $20-35$ & 0.39 & 1 & 17.5 & 210 & 59 \\
\hline $\begin{array}{l}\text { OCPUF@PDA } \\
\text { (TRIS)/Fe@Co }\end{array}$ & 0.4 & 0.4 & $2-40$ & $\mathbf{0}$ & - & 25.5 & 76.4 & This work \\
\hline
\end{tabular}

${ }^{\mathrm{a}}$ Carbon confined cobalt.

Table 3. Hydrogen production rate of metal decorated polydopamine catalysts.

\begin{tabular}{|c|c|c|c|c|}
\hline Catalyst & Chemical hydride (wt\%) & $\mathbf{T}\left({ }^{\circ} \mathbf{C}\right)$ & $\operatorname{HGR}\left(L \cdot h^{-1} \cdot g_{\text {cat }}{ }^{-1}\right)$ & Ref. \\
\hline Co/Pdop-o-MWCNT & $\mathrm{NH}_{3} \mathrm{BH}_{3}(76 \%)$ in water & 25 & 189.6 & 61 \\
\hline $\begin{array}{c}\text { OCPUF@PDA(TRIs)/Fe } \\
\text { @Co after seven runs }\end{array}$ & $\mathrm{NaBH}_{4}(0.4 \%)$ in alkaline water $(\mathrm{pH} 13)$ & 20 & 76.4 & This work \\
\hline
\end{tabular}

\section{CONCLUSION}

This work demonstrates that the lately introduced Soft Structured Catalytic Supports $\left(\mathrm{S}_{2} \mathrm{CS}\right)$ made of commercially available polyurethane open cell foam, coated under green conditions with a bio-inspired polydopamine (PDA) layer, can be functionalized with an earth-abundant $3 \mathrm{~d}$ metal, i.e.: cobalt.

Catalytic activity of PDA was observed for $\mathrm{H}_{2}$ release from an aqueous solution of $\mathrm{NaBH}_{4}$ prepared from a high purity $\mathrm{NaBH}_{4}$ powder. However, for a safe and easy-to-control portable $\mathrm{H}_{2}$ storage solution (e.g.: hydrogen production for a portable power system such as a fuel cell), the use of a stable alkaline $\mathrm{NaBH}_{4}$ solution is preferred. In this context, we have shown that our soft structured catalytic support based on a cobalt active phase is an efficient catalytic tool. The catalytic foam indeed exhibited a relatively good stability toward Co leaching and a catalytic activity for up to 10 runs (with a HGR of $76.4 \mathrm{~L} \cdot \mathrm{h}^{-1} \cdot \mathrm{g}_{\mathrm{cat}}{ }^{-1}$ ) for the hydrolysis of a commercially available stable alkaline $\mathrm{NaBH}_{4}$ solution. The HGR performance could be easy improved with the operating conditions (temperature, $\mathrm{pH}, \mathrm{NaBH}_{4}$ concentration...). Moreover, the cobalt-doped foam could be stored at room temperature under aerobic conditions for one week without alteration of its catalytic activity. 
In conclusion, this work based on a new class of soft structured catalytic solids brings several novelties in the domain of $\mathrm{H}_{2}$ production from catalysts and chemical hydrides sources: (i) the catalyst is supported on a simple, inexpensive, eco-friendly and commercially available open cell polyurethane foam, (ii) the preparation of the bio-inspired catalyst uses green chemistry conditions (water as solvent, room temperature, atmospheric pressure) and a low energy consuming process, (iii) in contrast to catalytic powders (often presented in literature) the structured catalytic tool facilitates the stock, load and recyclability operations, (iv) the lightweight and mechanical properties of the catalytic cobalt polyurethane foam are interesting features for portable applications, (v) the elastic properties of this new catalytic tools should allow the development of unexploited chemical reactors under continuous flow.

\section{ACKNOWLEDGEMENTS}

The authors thank the Agence Nationale de la Recherche (ANR 2016 PRCE 'POLYCATPUF') for financial support of this work.

\section{REFERENCES}

1. Abdin Z, Zafaranloo A, Rafiee A, Mérida W, Lipiński W, Khalilpour KR. Hydrogen as an energy vector. Renew Sustain Energy Rev. 2020;120:109620. doi:10.1016/j.rser.2019.109620

2. Marie-Rose De Valladares. Global Trends And Outlook For Hydrogen. . International Energy Agency, Hydrogen Technology Collaboration Program; 2017:5. https://ieahydrogen.org/pdfs/Global-Outlook-and-Trends-forHydrogen_Dec2017_WEB.aspx

3. Nikolaidis P, Poullikkas A. A comparative overview of hydrogen production processes. Renew Sustain Energy Rev. 2017;67:597-611. doi:10.1016/j.rser.2016.09.044

4. Aasberg-Petersen K, Christensen TS, Dybkjaer I, et al. Chapter 4 - Synthesis gas production for FT synthesis. In: Steynberg A, Dry M, eds. Studies in Surface Science and Catalysis. Vol 152. Fischer-Tropsch Technology. Elsevier; 2004:258-405. doi:10.1016/S0167-2991(04)80461-0

5. Dincer I, Acar C. Review and evaluation of hydrogen production methods for better sustainability. Int J Hydrog Energy. 2015;40. doi:10.1016/j.ijhydene.2014.12.035

6. Yilanci A, Dincer I, Ozturk H. A review on solar-hydrogen/fuel cell hybrid energy systems for stationary applications. Prog Energy Combust Sci. 2009;35:231-244. doi:10.1016/j.pecs.2008.07.004 
7. Redwood MD, Paterson-Beedle M, Macaskie L. Integrating dark and light bio-hydrogen production strategies: towards the hydrogen economy. Rev Env Sci BioTechnol. 2008;8:149-185.

8. Prabhukhot Prachi R, Wagh Mahesh M, Gangal Aneesh C. A Review on Solid State Hydrogen Storage Material. Insight Mech Eng. 2016;1(1). Accessed February 3, 2020. http://lawarencepress.com/ojs/index.php/IMEG/article/view/269

9. Hwang HT, Varma A. Hydrogen storage for fuel cell vehicles. Curr Opin Chem Eng. 2014;5:42-48. doi:10.1016/j.coche.2014.04.004

10. Midilli A, Ay M, Dincer I, Rosen MA. On hydrogen and hydrogen energy strategies: I: current status and needs. Renew Sustain Energy Rev. 2005;9(3):255-271.

11. Schlesinger HI, Brown HC, Finholt AE, Gilbreath JR, Hoekstra HR, Hyde EK. Sodium Borohydride, Its Hydrolysis and its Use as a Reducing Agent and in the Generation of Hydrogen ${ }^{1}$. J Am Chem Soc. 1953;75(1):215-219. doi:10.1021/ja01097a057

12. Kojima Y, Haga T. Recycling Process of Sodium Metaborate to Sodium Borohydride. Int J Hydrog Energy. 2003;28:989-993. doi:10.1016/S0360-3199(02)00173-8

13. Park EH, Jeong SU, Jung UH, et al. Recycling of sodium metaborate to borax. Int J Hydrog Energy. 2007;32(14):2982-2987. doi:https://doi.org/10.1016/j.ijhydene.2007.03.029

14. Fiorenza R, Scirè S, Venezia AM. Carbon supported bimetallic Ru-Co catalysts for H2 production through $\mathrm{NaBH} 4$ and $\mathrm{NH} 3 \mathrm{BH} 3$ hydrolysis. Int $J$ Energy Res. 2018;42(3):1183-1195. doi:10.1002/er.3918

15. Tuan DD, Lin K-YA. Ruthenium supported on ZIF-67 as an enhanced catalyst for hydrogen generation from hydrolysis of sodium borohydride. Chem Eng J. 2018;351:48-55. doi:10.1016/j.cej.2018.06.082

16. Liu M-R, Hong Q-L, Li Q-H, et al. Cobalt Boron Imidazolate Framework Derived Cobalt Nanoparticles Encapsulated in B/N Codoped Nanocarbon as Efficient Bifunctional Electrocatalysts for Overall Water Splitting. Adv Funct Mater. 2018;28(26). doi:10.1002/adfm.201801136

17. Pangarkar K, Schildhauer TJ, van Ommen JR, Nijenhuis J, Kapteijn F, Moulijn JA. Structured Packings for Multiphase Catalytic Reactors. Ind Eng Chem Res. 2008;47(10):3720-3751. doi:10.1021/ie800067r

18. Dai $\mathrm{P}$, Zhao $\mathrm{X}, \mathrm{Xu} \mathrm{D}$, et al. Preparation, characterization, and properties of $\mathrm{Pt} / \mathrm{Al} 2 \mathrm{O} 3 /$ cordierite monolith catalyst for hydrogen generation from hydrolysis of sodium borohydride in a flow reactor. Int J Hydrog Energy. 2019;44(53):28463-28470. doi:10.1016/j.ijhydene.2019.02.013

19. Boran A, Erkan S, Ozkar S, Eroglu I. Kinetics of hydrogen generation from hydrolysis of sodium borohydride on $\mathrm{Pt} / \mathrm{C}$ catalyst in a flow reactor: Kinetics of hydrogen generation. Int J Energy Res. 2013;37(5):443-448. doi:10.1002/er.3007 
20. Edouard D, Lacroix M, Pham-Huu C, Luck F. Pressure drop modeling on SOLID foam: State-of-the art correlation. Chem Eng J. 2008;144:299-311. doi:10.1016/j.cej.2008.06.007

21. Huu TT, Lacroix M, Pham Huu C, Schweich D, Edouard D. Towards a more realistic modeling of solid foam: Use of the pentagonal dodecahedron geometry. Chem Eng Sci. 2009;64(24):5131-5142. doi:10.1016/j.ces.2009.08.028

22. Richardson JT, Peng Y, Remue D. Properties of ceramic foam catalyst supports: pressure drop. Appl Catal Gen. 2000;204(1):19-32. doi:10.1016/S0926-860X(00)005081

23. Giani L, Groppi G, Tronconi E. Mass-Transfer Characterization of Metallic Foams as Supports for Structured Catalysts. Ind Eng Chem Res. 2005;44(14):4993-5002. doi: $10.1021 /$ ie 0490886

24. Huang Z-M, Su A, Liu Y-C. Hydrogen generation with sodium borohydride solution by Ru catalyst: Hydrogen generation with a sodium borohydride solution. Int J Energy Res. 2013;37(10):1187-1195. doi:10.1002/er.2937

25. Dai H-B, Liang Y, Wang P, Cheng H-M. Amorphous cobalt-boron/nickel foam as an effective catalyst for hydrogen generation from alkaline sodium borohydride solution. $J$ Power Sources. 2008;177(1):17-23. doi:10.1016/j.jpowsour.2007.11.023

26. Fusheng H, Zhengang $\mathrm{Z}$. The mechanical behavior of foamed aluminum. Published online 1998:9.

27. Engels H-W, Pirkl G, Albers R, et al. ChemInform Abstract: Polyurethanes: Versatile Materials and Sustainable Problem Solvers for Today's Challenges. Angew Chem Int Ed Engl. 2013;52. doi:10.1002/anie.201302766

28. Pardieu E, Chau NTT, Dintzer T, et al. Polydopamine-coated open cell polyurethane foams as an inexpensive, flexible yet robust catalyst support: a proof of concept. Chem Commun. 2016;52(25):4691-4693. doi:10.1039/C6CC00847J

29. Edouard D, Ritleng V, JIERRY L, DALENCON NTTC. Procede de modification des proprietes de surface de mousses cellulaires elastomeres. Published online January 28, 2016. https://patents.google.com/patent/WO2016012689A2/fr

30. Ait Khouya A, Mendez Martinez ML, Bertani P, et al. Coating of polydopamine on polyurethane open cell foams to design soft structured supports for molecular catalysts. Chem Commun. 2019;55(79):11960-11963. doi:10.1039/c9cc05379d

31. Fernandes R, Patel N, Kothari DC, Miotello A. Harvesting Clean Energy Through H2 Production Using Cobalt-Boride-Based Nanocatalyst. In: Chattopadhyay J, Srivastava R, eds. Advanced Nanomaterials in Biomedical, Sensor and Energy Applications. Springer; 2017:35-56. doi:10.1007/978-981-10-5346-7_3

32. Liu BH, Li Q. A highly active Co-B catalyst for hydrogen generation from sodium borohydride hydrolysis. Int $J$ Hydrog Energy. 2008;33(24):7385-7391. doi:10.1016/j.ijhydene.2008.09.055 
33. Jeong SU, Kim RK, Cho EA, et al. A study on hydrogen generation from NaBH4 solution using the high-performance Co-B catalyst. J Power Sources. 2005;144(1):129134. doi:10.1016/j.jpowsour.2004.12.046

34. Zhu J, Li R, Niu W, Wu Y, Gou X. Fast Hydrogen Generation From NaBH4 Hydrolysis Catalyzed by Carbon Aerogels Supported Cobalt Nanoparticles. Int J Hydrog Energy. 2013;38:10864-10870. doi:10.1016/j.ijhydene.2013.01.150

35. Andrieux J, Swierczynski D, Laversenne L, et al. A multifactor study of catalyzed hydrolysis of solid NaBH4 on cobalt nanoparticles: Thermodynamics and kinetics. Int $J$ Hydrog Energy. 2009;34(2):938-951. doi:10.1016/j.ijhydene.2008.09.102

36. Lefebvre L, Kelber J, Jierry L, Ritleng V, Edouard D. Polydopamine-coated open cell polyurethane foam as an efficient and easy-to-regenerate soft structured catalytic support (S 2 CS) for the reduction of dye. J Environ Chem Eng. 2017;5(1):79-85. doi:10.1016/j.jece.2016.11.025

37. Lee H, Dellatore SM, Miller WM, Messersmith PB. Mussel-Inspired Surface Chemistry for Multifunctional Coatings. Science. 2007;318(5849):426-430. doi:10.1126/science.1147241

38. Ponzio F, Barthès J, Bour J, et al. Oxidant Control of Polydopamine Surface Chemistry in Acids: A Mechanism-Based Entry to Superhydrophilic-Superoleophobic Coatings. Chem Mater. 2016;28(13):4697-4705. doi:10.1021/acs.chemmater.6b01587

39. Kim S, Gim T, Kang SM. Stability-enhanced polydopamine coatings on solid substrates by iron(III) coordination. Prog Org Coat. 2014;77(8):1336-1339. doi:10.1016/j.porgcoat.2014.04.011

40. Chinnappan A, Kang H-C, Kim H. Preparation of PVDF nanofiber composites for hydrogen generation from sodium borohydride. Energy. 2011;36(2):755-759. doi:10.1016/j.energy.2010.12.048

41. Kim JH, Lee M, Park CB. Polydopamine as a Biomimetic Electron Gate for Artificial Photosynthesis. Angew Chem Int Ed. 2014;53(25):6364-6368. doi:10.1002/anie. 201402608

42. Lefebvre L, Kelber J, Mao X, et al. Borohydride-functionalized polydopamine-coated open cell polyurethane foam as a reusable soft structured material for reduction reactions: Application to the removal of a dye. Environ Prog Sustain Energy. 2019;38(2):329-335.

43. Delgado JA, Claver C, Castillón S, Curulla-Ferré D, Ordomsky VV, Godard C. FischerTropsch synthesis catalysed by small $\mathrm{TiO} 2$ supported cobalt nanoparticles prepared by sodium borohydride reduction. Appl Catal Gen. 2016;513:39-46. doi:10.1016/j.apcata.2015.12.019

44. Wei W, Chen W, Ivey DG. Rock Salt-Spinel Structural Transformation in Anodically Electrodeposited Mn-Co-O Nanocrystals. Chem Mater. 2008;20(5):1941-1947. doi: $10.1021 / \mathrm{cm} 703464 \mathrm{p}$ 
45. Garcia-Torres J, Vallés E, Gómez E. Synthesis and characterization of Co@Ag coreshell nanoparticles. J Nanoparticle Res. 2010;12(6):2189-2199. doi:10.1007/s11051009-9784-x

46. Netskina OV, Kellerman DG, Ishchenko AV, Komova OV, Simagina VI. Amorphous ferromagnetic cobalt-boron composition reduced by sodium borohydride: Phase transformation at heat-treatment and its influence on the catalytic properties. Colloids Surf Physicochem Eng Asp. 2018;537:485-494. doi:10.1016/j.colsurfa.2017.10.052

47. Huang JH, Kargl-Simard C, Oliazadeh M, Alfantazi AM. pH-Controlled precipitation of cobalt and molybdenum from industrial waste effluents of a cobalt electrodeposition process. Hydrometallurgy. 2004;75(1-4):77-90. doi:10.1016/j.hydromet.2004.06.008

48. Du S, Liao Z, Qin Z, Zuo F, Li X. Polydopamine microparticles as redox mediators for catalytic reduction of methylene blue and rhodamine B. Catal Commun. 2015;72. doi:10.1016/j.catcom.2015.09.020

49. Ryou M-H, Lee DJ, Lee J-N, Lee YM, Park J-K, Choi JW. Lithium-Ion Batteries: Excellent Cycle Life of Lithium-Metal Anodes in Lithium-Ion Batteries with MusselInspired Polydopamine-Coated Separators (Adv. Energy Mater. 6/2012). Adv Energy Mater. 2012;2(6):610-610. doi:10.1002/aenm.201290031

50. Lhenry S, Leroux YR, Hapiot P. Use of Catechol As Selective Redox Mediator in Scanning Electrochemical Microscopy Investigations. Anal Chem. 2012;84(17):75187524. doi:10.1021/ac301634s

51. Paladini M, Arzac GM, Godinho V, et al. The role of cobalt hydroxide in deactivation of thin film Co-based catalysts for sodium borohydride hydrolysis. Appl Catal B Environ. 2017;210:342-351.

52. Hung A, Tsai S, Hsu Y, Ku J, Chen Y, Yu C. Kinetics of sodium borohydride hydrolysis reaction for hydrogen generation. Int J Hydrog Energy. 2008;33(21):62056215. doi:10.1016/j.ijhydene.2008.07.109

53. Holbrook KA, Twist PJ. Hydrolysis of the borohydride ion catalysed by metal-boron alloys. J Chem Soc A. 1971;(0):890-894. doi:10.1039/J19710000890

54. Kreevoy MM, Jacobson RW. The rate of decomposition of NaBH4 in basic aqueous solutions. Ventron Alembic. 1979:2-3.

55. Minkina VG, Shabunya SI, Kalinin VI, Martynenko VV. Stability of aqueous-alkaline sodium borohydride formulations. Russ J Appl Chem. 2008;81(3):380-385. doi:10.1134/S1070427208030051

56. Liu BH, Li ZP, Suda S. Nickel- and cobalt-based catalysts for hydrogen generation by hydrolysis of borohydride. $J$ Alloys Compd. 2006;415(1-2):288-293. doi:10.1016/j.jallcom.2005.08.019

57. Zhang X, Zhao J, Cheng F, Liang J, Tao Z, Chen J. Electroless-deposited Co-P catalysts for hydrogen generation from alkaline NaBH4 solution. Int J Hydrog Energy. 2010;35(15):8363-8369. doi:10.1016/j.ijhydene.2009.11.018 
58. Zhao J, Ma H, Chen J. Improved hydrogen generation from alkaline NaBH4NaBH4 solution using carbon-supported $\mathrm{Co}-\mathrm{BCo}-\mathrm{B}$ as catalysts. Int J Hydrog Energy. 2007;32(18):4711-4716. doi:10.1016/j.ijhydene.2007.07.004

59. Xu D, Zhang X, Zhao X, et al. Stability and kinetic studies of MOF-derived carbonconfined ultrafine Co catalyst for sodium borohydride hydrolysis. Int $J$ Energy Res. 2019;43(8):3702-3710. doi:10.1002/er.4524

60. Ye W, Zhang H, Xu D, Ma L, Yi B. Hydrogen generation utilizing alkaline sodium borohydride solution and supported cobalt catalyst. J Power Sources. 2007;164(2):544548. doi:10.1016/j.jpowsour.2006.09.114

61. Metin Ö, Özkar S. Hydrogen Generation from the Hydrolysis of Ammonia-borane and Sodium Borohydride Using Water-soluble Polymer-stabilized Cobalt( 0 ) Nanoclusters Catalyst. Energy Fuels. 2009;23(7):3517-3526. doi:10.1021/ef900171t

62. Levy Arthur, Brown JB, Lyons CJ. Catalyzed Hydrolysis of Sodium Borohydride. Ind Eng Chem. 1960;52(3):211-214. doi:10.1021/ie50603a022

63. Arthur EE, Li F, Momade FWY, Kim H. Catalytic hydrolysis of ammonia borane for hydrogen generation using cobalt nanocluster catalyst supported on polydopamine functionalized multiwalled carbon nanotube. Energy. 2014;76:822-829. doi:10.1016/j.energy.2014.08.080 